\title{
Deslindes lingüísticos en las tierras bajas del pacífico ecuatoriano. Primera parte
}

\author{
Jorge Gómez Rendón ${ }^{2}$
}

"Toda la tierra ques dicho-la situada entre la costa de Anegadizos y la Punta de Santa Elena-e aun la que se dirá, es de diversas lenguas, tanto que cada población tiene su lengua, e aunque con los vecinos se entienden, es con much a diversidad de vocablos mezclados con los otros comunes" (Gonzalo Fernández de Oviedo y Valdez, 1855: 121)

\section{RESUMEN}

EL CONOCIMIENTO de LAS LENGUAS QUE SE HABLARON EN LA REGión LITORAL DE NUESTRO PAís ANTES de LA CONQUiSTA

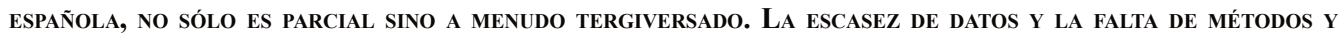
HERRAMIENTAS DE TIPO LINGÜÍSTICO ASÍ COMO LA DESCONTEXTUALIZACIÓN DE LOS DATOS FUERA DE UN MARCO SOCIO-

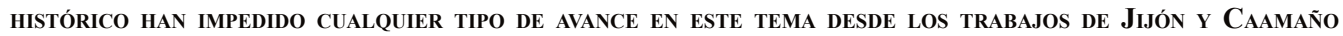
en los años cuarenta del siglo pasado. El presente artículo corresponde a la primera de tres partes DEDICADAS A TRAZAR LARR SITUACIÓN LINGÜÍSTICA DE LA COSTA ECUATORIANA EN TIEMPOS PREHISPÁNICOS EN BASE A UNA NUEVA SISTEMATIZACIÓN Y EVALUACIÓN DE LOS DATOS TOPONÍMICOS Y ANTROPONíMICOS DISPONIBLES PARA ESTA REGIÓN, COTEJÁNDOLOS EN TODO MOMENTO CON FUENTES ETNOHISTÓRICAS DE PRIMERA Y SEGUNDA MANO Y CON INFORMACIÓN MÁS RECIENTE DE TIPO ARQUEOLÓGICO PARA LA COSTA DE NUESTRO PAís. EN ESTE MARCO SE OFRECE ADEMÁS UNA APROXIMACIÓN CRÍTICA A LOS CONTADOS ESTUDIOS LINGÜÍSTICOS SOBRE EL TEMA Y SE DEFINEN ALGUNAS PAUTAS METODOLÓGICAS QUE DEBEN GUIAR TODO ESTUDIO TOPONÍMICO Y ANTROPONÍMICO QUE BUSQUE SUPERAR LAS PRÁCTICAS COMUNES EN AMBAS ÁREAS DE INVESTIGACIÓN.

Palabras claves: Lingüística amerindia, Toponimia, Antroponimia, Lenguas precolombinas, Litoral PACÍFICO.

\section{Abstract}

THE KNOWLEDGE OF THE LANGUAGES SPOKEN IN THE ECUADORIAN PACIFIC LOWLANDS BEFORE THE SPANISH CONQUEST IS BOTH PARTIAL AND BIASED. THE SCARCITY OF DATA AND THE LACK OF PROPER LINGUISTIC METHODS AND TOOLS OF ANALYSIS AS WELL AS THE PRESENTATION OF LINGUISTIC DATA OUT OF THEIR SOCIAL AND HISTORICAL CONTEXT, HAVE

1 La parte teórica del presente artículo fue preparada en el marco del proyecto de rescate patrimonial de las comunas de la cuenca del río Valdivia en la Península de Santa Elena, llevado adelante por el Instituto Nacional de Patrimonio Cultural en su regional del Guayas entre septiembre y diciembre de 2010.

2 Universidad de Ámsterdam 
PREVENTED US FROM MAKING ANY PROGRESS IN THIS AREA SINCE THE WORK BY JiJón Y CAAMAÑo IN THE 1940s. THIS ARTICLE CORRESPONDS TO THE FIRST OF THREE PARTS WHICH FOCUS ON THE LINGUISTIC SITUATION OF THE ECUADORIAN PACIFIC LOWLANDS. IT IS BASED ON A NEW SYSTEMATIZATION AND EVALUATION OF TOPONYMS AND ANTHROPONYMS AVAILABLE FOR THIS AREA AND THEIR COMPARISON WITH FIRST- AND SECOND-HAND HISTORIC AND ARCHAEOLOGICAL INFORMATION PRODUCED IN THE LAST DECADES. IN ADDITION, THE ARTICLE PROVIDES A CRITICAL APPROACH TO THE FEW LINGUISTIC STUDIES ON THE TOPIC OF PRE-COLUMBIAN LANGUAGES AND SEVERAL METHODOLOGICAL CRITERIA FOR ANY STUDY OF TOPONYMY AND ANTHROPONOMY WHICH SEEKS TO OVERCOME THE SHORTCOMINGS OF PREVIOUS PRACTICES IN THIS AREA OF RESEARCH.

Keywords: Amerindian linguistics, Toponymy, Anthroponomy, Pre-columbian languages, Pacific LOWLANDS.

\section{Introducción}

$\mathrm{E}$ xisten hoy en día en el Ecuador trece lenguas indígenas, de las cuales cuatro se hablan en la región litoral del país (ver Anexos, Mapa 3). El cha'palaa, el awapit y el sia pedee se hablan en la provincia de Esmeraldas mientras el tsa'fiki se habla en la provincia de Santo Domingo de los Tsa'chilas. El resto de la Costa es monolingüe en castellano ${ }^{3}$. Pero no siempre lo fue. La castellanización de la Costa ecuatoriana es un proceso de varios siglos que dio inicio con la conquista y continúa hasta el presente. Cronistas como el que citamos en el epígrafe, sostienen que al momento de la llegada de los primeros españoles, se hablaban a lo a largo de la Costa un número mucho mayor de lenguas. Exceptuando aquellas que acabamos de mencionar, del resto de lenguas que alguna vez se hablaron en la región litoral de nuestro país, no ha llegado a nosotros ni un solo documento que nos permita su estudio o al menos su clasificación filogenética en alguna de las familias lingüísticas conocidas ${ }^{4}$. Pero, si un estudio o recuperación a la manera que se lleva a cabo para otras lenguas indígenas del país (cf. Gómez Rendón, 2008; 2010) no es posible con las extintas de la Costa, (como tampoco con las lenguas prehispánicas a las cuales desplazó el kichwa en el callejón interandino) sí es posible emprender una tarea de "arqueología lingüística", a fin de perfilar la composición de las lenguas originarias de esta región, explorar las relaciones lingüísticas entre los pueblos que la habitaban antes de la conquista, y conocer la configuración social y los contactos culturales dentro del espacio regional y fuera de él. Para ello disponemos no sólo de valiosas noticias que reposan en fuentes históricas primarias y secundarias, sino también de datos lingüísticos "en bruto", casi siempre en forma de topónimos o antropónimos y en algún caso de una que otra frase con su glosa. Abandonada en los ya de por sí exiguos estudios lingüísticos de nuestro país desde hace setenta años (Jijón y Caamaño, 1940-1945), la tarea de recuperar, reorganizar y reanalizar la toponimia y la antroponimia a la luz de nuevos enfoques y con herramientas más precisas es la que asumimos aquí, conscientes de las limitaciones que impone una investigación de esta naturaleza, bien por la insuficiencia, bien por incertidumbre de los datos disponibles, los cuales han de pasar primero por varias cribas antes de poder servir al análisis lingüístico.

3 Esta afirmación resulta un tanto simplista pues no toma en cuenta a los más de 200.000 hablantes del kichwa serrano que viven hoy en día en Guayaquil. En cualquier caso, el kichwa no es originario de esta región y su presencia se debe a un movimiento migratorio que empezó antes del siglo veinte, razón por la cual no puede ser considerada una lengua originaria de la costa ecuatoriana.

4 La excepción es el esmeraldeño, lengua indígena hablada hasta finales del siglo pasado en el curso inferior del río Esmeraldas, de la cual nos quedan, gracias a las diligencias del geógrafo alemán Teodoro Wolf, un vocabulario de más de un centenar de palabras y un buen número de frases con sus respectivas glosas castellanas. 
La contribución que el lector tiene en sus manos persigue un doble propósito: exploratorio, en la medida que espiga datos de un diverso número de fuentes, históricas, demográficas y lingüísticas; probatorio, en cuanto comprueba o desecha antiguas hipótesis y sugiere otras nuevas a partir de los resultados obtenidos. Adicionalmente, ofrece criterios metodológicos para el uso crítico, interdisciplinario y científico de los datos, criterios que consideramos imprescindibles para obtener resultados concretos que vayan más allá de las listas de palabras y las falsas etimologías, prácticas inveteradas de nuestros estudios toponímicos y antroponímicos que han de ser extirpadas de raíz.

La segunda sección presenta un bosquejo de la situación lingüística y cultural de la Costa ecuatoriana antes de la llegada de los españoles, como marco para la interpretación de los datos lingüísticos. La tercera sección ofrece un vistazo a los cambios producidos a raíz de la invasión española en lo demográfico y socioeconómico, dos factores fundamentales para entender la dinámica sociolingüística. La cuarta sección comprende una presentación y evaluación de los estudios lingüísticos disponibles sobre la Costa ecuatoriana en la época prehispánica, pues hubo esfuerzos que nos precedieron, aunque por su temprana aparición no pudieran beneficiarse de los avances hechos en la arqueología, la etnohistoria y el análisis lingüístico desde la segunda mitad del siglo pasado. En la quinta sección discutimos toda la problemática de la metodología del estudio toponímico y antroponímico, subrayando la necesidad de trabajar tanto en el campo como en los archivos, de aproximarse a los datos de manera crítica desde diferentes disciplinas, de tomar en cuenta los últimos desarrollos teóricos de la lingüística, y de incorporar el manejo de bases digitales y otras herramientas informáticas para un estudio más eficaz y preciso de los datos.

Las partes segunda y tercera del artículo, que aparecerán en entregas posteriores, están dedicadas, respectivamente, a la descripción y al análisis de datos toponímicos de diversas fuentes, así como a trazar deslindes lingüísticos a partir de los resultados obtenidos y comprobar relaciones filogenéticas con lenguas y familias lingüísticas del Área Septentrional Andina.

\section{La Costa del Ecuador antes de la conquista española}

La Costa ecuatoriana muestra una larga historia de ocupación que empieza desde aproximadamente diez mil años antes de nuestra era, con el complejo Las Vegas (9.050 a.C. 4.650 a.C.), ubicado en la parte occidental de la Península de Santa Elena, el principal de los complejos pre-cerámicos del litoral (Stothert, 1983; 1985; 1988). Desde finales del paleoindio (4.500 a.C.) tiene lugar en toda la Costa - pero con especial concentración en la zona centro-sur - una evolución cultural prácticamente ininterrumpida, con las culturas Valdivia (4.000-1.940 a.C.), Real Alto (3.200 a.C.), Machalilla (2.250-1.320 a.C.) y Chorrera (1.300-500 a.C.) en el Período Formativo, y las de Jambelí, Guangala, Bahía, Jama-Coaque y Tumaco-La Tolita en el período de Desarrollos Regionales (500 a.C. - 500 d.C.). En los cinco mil años que transcurren desde los primeros asentamientos de origen valdiviano hasta los años postreros de culturas como Bahía y Guangala, se observa una complejización de las formas de poblamiento, pasando de asentamientos dispersos y nucleados a conglomerados de carácter urbano, como efecto de un notable desarrollo agrícola, artesanal y comercial (Echeverría, 1996: 200).

Una explosión demográfica asociada con el sedentarismo y la productividad agrícola parece haber llevado, en el período de integración, a formas de organización política del tipo señorío, de la mano de una diferenciación social en aumento, sin llegar a la formación de estados ni a la estratificación social compleja asociada con los imperios del sur andino. Paralelamente al desarrollo de formas sociales y políticas más complejas, se fueron multiplicando expresiones de la cultura material e inmaterial, plasmadas en la alfarería, la arquitectura, las festividades, la religión y las técnicas de navegación. Para los albores del siglo XVI se asume para la Costa ecuatoriana la existencia de al menos tres culturas diferenciadas pero estrechamente relacionadas: 
la Atacameña, la Milagro-Quevedo y la Manteño-Huancavilca. Pergeñemos ahora un perfil de cada una en base a la evidencia histórica.

La relación del viaje de reconocimiento de Bartolomé Ruiz nos ofrece un buen punto de partida. Saliendo de la Isla del Gallo, Ruiz llega a la Bahía de San Mateo en el extremo norte de nuestras costas y encuentra tres pueblos donde "no había diferencia de la manera de los indios más de cómo Panamá" (Sámanos, 1884 [1526]: 196). La región donde encuentra el cronista una estrecha similitud en sus pobladores es conocida actualmente como el Chocó, que efectivamente se extiende desde el Darién panameño hasta el extremo norte del litoral esmeraldeño. Más todavía, la similitud sociocultural de los pueblos que habitan esta región se refleja en la existencia de un continuo de dialectos y lenguas estrechamente emparentadas que conforman la familia lingüística chocoana (Campbell, 1997: 172s).

Siguiendo la costa hacia el sur, los exploradores encuentran "otro pueblo que estaba cuatro leguas de allí, muy grande, que se dice Tacamez” (Sámanos, 1884: 198). En base a la evidencia arqueológica y etnohistórica actual, es posible asociar Tacamez con el núcleo principal de la cultura atacameña. Ésta se desarrolló a partir del complejo Jama-Coaque del período regional, durante el cual también floreció en la costa sur de Esmeraldas la cultura Tiaone (Estrada y Evans 1963). A propósito, al hablar de la costa sur de Esmeraldas Cieza distingue dos tipos de gente: unos, dice el cronista, son gente que se "labra" el rostro; otros, por el contrario, no tienen dicha costumbre. Jijón asocia a los de rostro pintado, que Cieza llama 'Caráquez'5 , con los hablantes del antiguo esmeraldeño (Jijón, 1941: II-103). A principios del siglo pasado Seler (1902: 52) sostenía que el esmeraldeño se hablaba desde el extremo norte de la Costa ecuatoriana hasta Bahía de Caráquez. Un estudio reciente sugiere además una posible afinidad, provocada por contacto, con la lengua de los manteño-huancavilcas (Adelaar, 2005).

Al proseguir su itinerario hacia el sur, la expedición de Bartolomé Ruiz halla numerosos pueblos asentados en tierra llana pero sobre todo una "población que duraba una legua o más (que al paresçer serían quinientos buhíos) e las labranzas cerca dellos [...] e tierra de pocos ríos" (Estete, 1919: 314). Desafortunadamente el cronista no precisa el nombre de la población. Más tarde, Ruiz sabrá de boca de tres indios que capturó para intérpretes, que provenían de un pueblo llamado Calangone, compuesto por cuatro pueblos juntos, el mismo Calangone, Tuses, Saracapez y Salango, gobernados todos por un solo señor, el cual además gobernaba a los indios de la costa que estaba más al norte, incluyendo los de Tacamez, los de la Bahía de San Mateo y otras poblaciones como Conilope, Arampajos, Coaque, entre otras (Sámanos, 1884: 200). Esta red de poblaciones esparcidas a lo largo de la costa manabita y su interior, incluyendo el señorío

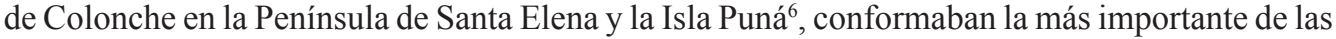
culturas prehispánicas de la Costa ecuatoriana: la cultura manteña y su variante huancavilca ${ }^{7}$.

5 Jijón señala que pese a la tendencia a clasificar Caráquez como una voz barbacoa por su última sílaba, muy similar a la final -qui, es más correcto asociarla con el esmeraldeño, donde cara equivale a 'colorado' y quiam significa 'casa'. Sin embargo, desde el punto de vista del cambio fonético es más probable que un segmento original [-kes] devenga [ki] por elisión de la sibilante final, que una nasal [m] mude en sibilante [s] y que el diptongo [ia] se disuelva en un núcleo vocálico simple [e]. En vista de ello creemos que la propuesta de Jijón requiere un mayor cotejo de datos lingüísticos a partir de lo que sabemos sobre el esmeraldeño.

6 No existe un acuerdo en las fuentes con respecto a la pertenencia o no de Puná y su población a la sociedad manteñohuancavilca, lo cierto es que sus habitantes participaban activamente del tráfico costero como los demás pueblos del literal ecuatoriano, sobre todo con la costa norte peruana.

7 El arqueólogo guayaquileño Carlos Zevallos Menéndez sostiene lo contrario, a saber, que la cultura Huancavilca es el origen de la Manteña, por ser aquella la más antigua. Zevallos Menéndez concuerda con la propuesta de Estrada y Jijón sobre la existencia de una confederación de mercaderes y sostiene que en realidad la similitud en la cultura material de las sociedades manteña y huancavilca se debe más bien a la comunión de objetos intercambiados a través de redes comerciales, y que subsisten importantes diferencias en las dos. El autor plantea incluso una penetración exclusivamente huancavilca - no manteña - en la cuenca baja del Guayas, incluyendo el Estero Salado, el Canal del Morro y la zona de Chongón, hasta la parte inferior del Daule (Zevallos Menéndez 1992: 254ss). 
Las primeras crónicas sugieren que el Litoral Pacífico del Ecuador tenía una importante población y que dicha población estaba organizada en una especie de señoríos, sujetos todos, o su gran mayoría, a uno principal. Es muy probable que hubiera para esta época una considerable población desde el hinterland costero hasta el piedemonte andino occidental. Poco se sabe sobre la demografía de esta región y su organización sociopolítica ${ }^{8}$. Hoy en día conocemos la existencia de asentamientos del interior tales como Cerro de Hojas, Cerro Jaboncillo, Cerro Montecristi y Agua Blanca, de los cuales se ha dicho que cumplían funciones ceremoniales en la sociedad manteño-huancavilca, en comparación con la función más portuaria y comercial desempeñada por los poblados costeros (McEwan, 2003). En este sentido se ha sugerido que la organización espacial de la sociedad manteño-huancavilca se basaba en una división este-oeste que le permitía un mejor control de la producción a través de la articulación de medioambientes que iban desde la franja costera hasta las cordilleras del interior (Álvarez, 2001: 140). En términos generales, los estudios etnohistóricos y las excavaciones arqueológicas realizadas en Manabí desde principios del siglo pasado dan cuenta de una sociedad con un alto grado de organización política, que sin llegar a ser una formación estatal estaba estrechamente cohesionada por un conjunto de rasgos culturales y una amplia red de relaciones comerciales ${ }^{9}$.

A propósito del comercio prehispánico, tan importante para comprender el orden social y cultural prehispánico como para trazar posibles relaciones lingüísticas entre los pueblos concernidos, la referencia más viva que tenemos de él es la que nos ofrece Sámanos al referirse a la famosa embarcación indígena que Ruiz encontró frente a las costas de Manabí en su viaje de exploración. Se trataba de una gran embarcación a vela que transportaba personas y mercancías. De sus veinte ocupantes, tres fueron tomados como intérpretes, según hemos dicho. Llevaba la embarcación manabita un sinnúmero de mercancías, desde cántaros, camisas, paños, ropa de diversos colores y con distintos motivos, piezas de plata, cascabeles, e incluso instrumentos para tasar y pesar el oro. Mas de toda la carga el material precioso eran las "conchas coloradas [...] e por estas dan los indios todo el oro e plata e ropas que traen de rescate" (Sámanos 1884: 200). Las "conchas coloradas" no son otras que aquellas del género Spondylus, que junto con las caracolas del género Strombus constituyen dos de los objetos rituales más importantes del área andina, asociados con el culto a la lluvia y la fertilidad, no sólo en el litoral sino también a lo largo de la cordillera de los Andes. Del comercio de 'mullu' (Spondylus princeps) a lugares tan lejanos como las costas del Pacífico mexicano y el norte de Chile se encargaba un grupo selecto de comerciantes a larga distancia que habían desarrollado un extenso conocimiento de la navegación y las rutas marinas, en un proceso que habría durado más de cuatro mil años desde los primeros tiempos de la cultura Valdivia (Lathrap, et al, 1977). Fue precisamente en las costas del litoral ecuatoriano, desde el cabo de San Lorenzo hasta la Punta de Santa Elena, donde se originó el rito propiciatorio a la lluvia en torno a la 'concha colorada' (c. 3.200 a.C.); de allí pasaría a los Andes septentrionales y centrales y en una tercera etapa hacia Mesoamérica (Marcos, 1995: 99).

Dentro de este tráfico a larga distancia el mullu constituye no sólo un elemento de difusión cultural dentro y fuera de los Andes, sino también una forma compleja de relación entre sociedades con diferentes niveles de organización política. En el seno de esta matriz comercial, según Zeidler, "las formaciones sociopolíticas de la costa del Ecuador mantuvieron su autonomía

8 Pedro de Alvarado, el primer europeo que se viajó tierra adentro desde las costas de Manabí hasta llegar a la sierra de Angamarca, no nos ha dejado ninguna relación de su viaje de varios meses.

9 Las primeras excavaciones arqueológicas estuvieron a cargo de George Dorsey, que trabajó en la Isla de la Plata (1901), y más tarde de Marshall Saville, quien emprendió una extensa investigación en las costas de Manabí (1907). Jijón y Caamaño realizó excavaciones en la antigua Jocay y en el Cerro de Jaboncillo en la década siguiente (1917, 1923). Continuó el trabajo de estos pioneros Emilio Estrada en la década de los años cincuenta y sesenta, sobre todo en la costa sur de Manabí (1957; 1962). Desde el año 2003 se han venido realizando trabajos arqueológicos en la parte central de la provincia, en especial en los pueblos de Chirije y Japotó (Bouchard et al 2006). 
geopolítica como mercaderes-traficantes en la frontera de sucesivos imperios andinos" (Zeidler, 1991: 262).

La importancia del tráfico de Spondylus radica en la creación de un espacio de contacto lingüístico y cultural entre diferentes pueblos, el cual bien pudo haber conducido a la mezcla de lenguas, o bien a la creación y utilización de una lengua vehicular que facilitara los intercambios, desarrollo bien conocido en otras situaciones de tráfico a larga distancia, por ejemplo, en la Polinesia y Oceanía. Rabinowitz sugiere precisamente que comunidades que tienen una gran movilidad y que participan activamente en actividades comerciales, suelen desarrollar su propio pidgin para facilitar la comunicación ${ }^{10}$; una de estas lenguas habría sido precisamente la que se conoce como 'pescadora', hablada alguna vez en la costa central del Perú (Rabinowitz, 1982: 258s), que se desarrolló a partir de la particularidad del medioambiente costero, de la especialización mercantil para la subsistencia y del aislamiento social de las comunidades pescadoras.

Es necesario, por lo tanto, que nos preguntemos cuál fue la lengua que hizo posible los intercambios comerciales en el Área Septentrional Andina y Centro Andina. Un vistazo a las rutas comerciales podría arrojar luz sobre los pueblos involucrados y sus relaciones culturales y lingüísticas. Lo cierto es que si asumimos que el comercio fue una de las principales actividades de la sociedad manteño-huancavilca, el nacimiento de una lengua vehicular para facilitar dicho comercio es más que obvio. Desafortunadamente no tenemos evidencia lingüística que corrobore esta afirmación, aunque es del todo posible rastrear la variedad lingüística del territorio manteñohuancavilca a partir de su toponimia y antroponimia ${ }^{11}$.

Es interesante que en el Área Septentrional Andina la presencia de mullu se encuentre ya desde las primeras fases de Cerro Narrío y Chaulabamba (1.800-1.100 a.C.) en las actuales provincias de Cañar, Azuay y Loja, y más tarde, en el período de integración, en La Florida (Quito). Desde los Andes australes del Ecuador pasará el mullu a los Andes centrales, sobre todo durante la fase Chavín (1.200-300 a.C.), aumentando exponencialmente la demanda de la concha con el surgimiento de los reinos de Wari (700-1.000 d.C.) y Chimor (1.100-1470) y el imperio inca (1.470-1.532). En los últimos tiempos, sin embargo, el papel de los comerciantes-traficantes de mullu de la costa manabita pudo haber disminuido por la participación de comerciantes del valle peruano de Chincha y más tarde por los mollo chasqui camayoc cuzqueños (Rostworowski, 1975: 338). En todo caso, es posible que el ámbito de influencia de los navegantes manteños no llegara más allá de la costa tumbesina debido al problema que representa la corriente fría de Humboldt para la navegación. En efecto, se sabe que para el abastecimiento de la concha a los Andes centrales, se prefería el transporte por tierra desde Tumbes o a través de territorio cañarí (Hocquenghem, 1993: 707).

Para los Andes del Ecuador se han identificado al menos cinco rutas para la distribución de Spondylus, bien a través de los conocidos mindaláes de los señoríos serranos, de los yumbos de la ceja de montaña, o de los propios navegantes manteño-huancavilcas de la costa de Manabí hasta la Puná:

10 Un pidgin es una lengua simplificada utilizada en las relaciones comerciales. Su léxico normalmente está conformado por el de lenguas de prestigio y amplia distribución mientras que las matrices gramatical y léxica provienen de otras lenguas componentes (Crystal 2006: 354).

11 Durante la redacción del presente artículo conocimos de un importante descubrimiento que apoya de varias maneras la tesis de la mezcla lingüística como producto de relaciones comerciales. Se trata de una breve lista de números en una lengua indígena que se hablaba en el siglo dieciséis en la reducción de Magdalena de Cao en la costa norte peruana. Pese a su brevedad, la lista proporciona valiosa información sobre el sistema numérico nativo, la influencia de la lengua kichwa en el mismo, y las posibles relaciones con otras lenguas vecinas. Aunque los investigadores que publican el informe no están del todo seguros de qué lengua se trata, dan por hecho que no es el mochica y sostienen que la evidencia apunta más bien a la lengua 'pescadora' de la que propuso Rabinowitz su origen en un pidgin altamente desarrollado (Quilter et al 2010: 357-369). Por su origen costero, su dedicación al comercio y su cercanía con la costa centro-sur del Ecuador, la lengua 'pescadora' puede resultar una buena candidata para explorar posibles relaciones genéticas con la lengua manteño-huancavilca u otras de la costa. 
“1) desde Esmeraldas y Tumaco a través de los ríos Mira y San Juan hacia las hoyas de Carchi e Imbabura; 2) desde Esmeraldas y el norte de Manabí a través de los ríos Guayabamba y Toachi a la hoya de Quito; 3) desde las costas de Manabí central y sur, y de la provincia del Guayas, a través de la cuenca superior del Guayas a la región ocupada por las provincias de Cotopaxi, Tungurahua, Bolívar y Chimborazo; 4) desde el sur de Manabí, la Península de Santa Elena, el Golfo de Guayaquil a través de la baja cuenca del Guayas a las provincias de Cañar, Azuay y Loja; una quinta red de intercambio relacionaba al sur de la Provincia de El Oro, al extremo norte del Perú con las provincias de Loja, Azuay y Cañar. Estas rutas de unión entre la costa y la sierra del Ecuador prehispánico se articulaban con las que seguían las cuencas del Napo, del Tigre, del Pastaza, del Morona y del Santiago" (Marcos, 1995: 115).

Aunque la extracción de Spondylus debió haber involucrado a un grupo de pescadores especializados por la dificultad que implica su obtención en aguas profundas, es seguro que dada la alta demanda de la concha varios pueblos a lo largo de la costa ecuatoriana se dedicaran a su extracción. Por otro lado, la distribución y el consumo del mullu involucraban decenas de pueblos prehispánicos tanto en la costa y la sierra del Ecuador como en los Andes centrales y la costa desértica peruana. Pese a la enorme importancia del mullu en la vida de los pueblos de nuestro litoral prehispánico, su extracción no era la única actividad de sostenimiento; así lo demuestra la existencia de importantes sistemas de regadío a través de albarradas y, sobre todo, de campos elevados o camellones y terrazas agrícolas que se han encontrado en particular en la provincia del Guayas (cf. Marcos, 1987). Sólo a partir de una base agrícola que producía excedentes y una red de intercambio que permitía el control de un elemento ritual fundamental para la reproducción cultural de los pueblos andinos pudo llegar a formarse una sociedad de organización compleja que en nada se asemeja a la "behetrías" que encontró Ruiz en el litoral pacífico colombiano. Para la cultura manteño-huancavilca (800-1530) se ha propuesto incluso la formación de un Estado en base a la acumulación de capital mercantil, que posibilitó el tráfico de Spondylus, la diferenciación funcional vertical de algunos de sus grupos, y la especialización y estandarización de la producción no sólo dentro de un mismo centro urbano sino entre centros, a fin de maximizar el aprovechamiento de microambientes (Marcos, 1995: 127ss). Se ha sostenido incluso, que la existencia de las famosas sillas de piedra en $U$ o asientos de poder que se encuentran en diferentes sitios arqueológicos de la costa centro-sur, serían un indicio claro de la jerarquía y la estratificación social del naciente estado huancavilca. No es nuestro objetivo aquí discutir sobre la existencia o no de un estado huancavilca; nos interesa más bien rastrear la red de intercambios y contactos establecidos por las poblaciones pertenecientes a la cultura manteñohuancavilca con otras del callejón interandino y la costa norte peruana, pues es precisamente con estas áreas con las que se ha postulado una posible filiación genética de las lenguas prehispánicas de la Costa. En efecto, Jijón sostiene que el análisis lingüístico comparativo de la toponimia y la antroponimia de la Costa y la Sierra centro-sur del Ecuador con la Costa norperuana obliga a reconocer un estrecho parentesco entre las lenguas puruhá (Chimborazo y norte del Azuay), cañari (Azuay y norte de Loja), manteño-huancavilca (Manabí, Santa Elena, Guayas, Los Ríos y el Oro), y mochica (costa norte del Perú) (Jijón y Caamaño, 1943: III-462ss). En la tercera parte de este estudio tendremos más que decir sobre esta propuesta. Por el momento basta señalar que el compartir elementos de la cultura material dentro de un área cultural, no implica de suyo un parentesco lingüístico entre los diferentes pueblos que la conforman. Antes bien, sugiere una posible convergencia del léxico y la gramática de las lenguas involucradas, que resulta en la creación de rasgos areales como se ha postulado, por ejemplo, para el sudeste de Asia o para la parte noroccidental de la cuenca amazónica (Aikhenvald, 2010).

Hasta aquí hemos mencionado las culturas prehispánicas atacameña y manteño-huancavilca. La tercera cultura prehispánica que florecía en la costa ecuatoriana al momento de la invasión española se conoce como Milagro-Quevedo y está asociada directamente con el llamado reino chono. Ocupó la mayor parte del sistema fluvial del Guayas, sobre todo el curso medio y superior de los ríos Daule y Babahoyo, pero también la provincia de El Oro e incluso, según algunos 
autores, el norte peruano (Pérez Pimentel, 2003, I: 14ss). Una descripción minuciosa de la extensión del reino chono la encontramos en Espinoza Soriano $(1981,1988)$, la misma que transcribimos a continuación:

"El área geográfica de los Chono, llamados Daulis o Daules por los españoles, según se deduce de estos documentos [crónicas y expedientes], conformaban todo lo que hoy constituyen los cantones, parroquias y lugares de El Balzar, Quevedo, Mocache, Palenque, Colimes, Vinces, Guare, Las Ramas, Baba, Pimocha, Babahoyo, Daule, Chilintomo, Juján, Sambor, Lorenzo Garaicoa, Yaguachi, Chobo, Milagro, Buca, Naranjito, San Andrés, Taura, Cone, Jelí, Churute, Jesús María, El Naranjal, Balao y Tenguel, más La Soledad, Chonanas y Colimes al oeste del río Daule y norte de Guayaquil. Pero parece que también comprendía los cantones y parroquias de Olmedo, Ayacucho, Junín, Bolívar, Canuto y Chone, situados al sur de la provincia de Manabí, en los límites con la de Guayaquil. Los Chonos, en consecuencia, como los demás habitantes de los términos jurisdiccionales de la ciudad de Guayaquil, estuvieron incluidos dentro de la población yunga" (Espinoza Soriano, 1988: 131)

Este autor señala el error incurrido por varios historiadores ecuatorianos - desde González Suárez (1967 [1915]), pasando por Jijón y Caamaño (1919), hasta los esposos Costales (1961) - en considerar a los chonos como una parcialidad huancavilca. Aunque es evidente que al pertenecer al área cultural de la región septentrional andina occidental ambos pueblos compartieran rasgos de su cultura material - por ejemplo, el uso del palo de balsa para la construcción de embarcaciones o los sepulcros abovedados con la entrada hacia el este - existían también otros que eran propios del pueblo chono - como los ornamentos nasales y auriculares o la vestimenta exclusiva de algodón.

Por excavaciones realizadas ya desde inicios del siglo veinte (Buchwald, 1918, 1926) y noticias tempranas provenientes sobre todo de relaciones geográficas del siglo dieciséis, sabemos que los chonos ${ }^{12}$ no sólo fueron diestros orfebres y navegantes, sino que además su sociedad tenía una fuerte base agrícola, cuya productividad era posible gracias a la construcción de tolas o camellones, es decir, campos agrícolas elevados sobre superficies anegadizas para intensificar los cultivos y reducir la salinidad del agua (Meggers, 1966: 133; Álvarez, 2002: 187ss). El mismo tipo de tolas asociadas con la intensificación agrícola se encuentran en las tierras altas de Cayambe, área de asentamiento del pueblo prehispánico cara, al que se acostumbra vincular con la familia de lenguas barbacoas, junto con el awa, el tsáchila y el pasto. No deja de ser sugerente que hasta finales del siglo diecinueve el pueblo tsáchila habitara en las cabeceras del Daule y el Babahoyo, retirándose a su actual zona de asentamiento más al norte sólo en el transcurso del siglo veinte. Su ocupación de la cuenca superior del Guayas y la proliferación de una toponimia de claro origen barbacoa en la zona han servido para postular que el llamado reino chono que encontraron los españoles estaba estrechamente emparentado con los históricos tsáchilas o colorados. Así, apoyándose en Borja de Szászdi (1964), Newson sostiene que:

"casi no hay duda de que los Chono fueran ancestros de los Colorados, así llamados por pintarse el cuerpo de rojo, y que éstos representan los residuos de un grupo otrora extenso que desde la época de la conquista española vivía en la parte norte, en las cabeceras de los ríos Esmeraldas y Daule, siendo sus principales asentamientos Santo Domingo de los Colorados y San Miguel" (Newson 1995: 74ss, mi traducción).

12 No podemos asegurar, sin embargo, si se trata de un autónimo o un exónimo, siendo más posible lo segundo, pues parece que la palabra chono - para unos de origen mochica, para otros tallán - significaba 'perro', siendo utilizada por los incas y otros pueblos de la costa norte peruana para referirse a individuos y grupos que consideraban inferiores. Así, por ejemplo, parece que los indios de la Puná endilgaban este epíteto a los habitantes del Daule cada vez que los encontraban en el mar. Es más probable que su autónimo haya sido el de Daules, o bien el de Chaunes, por su cacique principal, Chaune El Viejo (Espinoza Soriano 1988: 144, 145). Alternativamente, es posible que el gentilicio ‘chono' fuera una corrupción de 'chaune' a partir de la pronunciación española de esta palabra. 
Por su parte, Estrada (1957a: 238) y Borja de Szászdi (1964: 411) afirman, muy probablemente en base a las sugerencias de Jijón (1919; 1941), que la lengua hablada por los chonos era la misma que la hablada por los Cayapas y los Colorados. A su vez, Zevallos Menéndez cree que la presencia de los llamados Colorados en el sistema fluvial del Daule se debió a una de las primeras oleadas nómadas - "algunos milenios antes de la era cristiana" - que se asentaron por toda la cuenca del Guayas. En este caso, los Colorados o Tsáchilas no serían los Chonos, sino más bien "el basamento autóctono de los pobladores de la Cuenca del Guayas y gran parte de la costa ecuatoriana [y] sobre este substrato de variada etnia se introdujo la costumbre bastante generalizada de construir montículos artificiales" (Zevallos Menéndez, 1992: 259s). Del mismo modo, la abundantísima presencia de raíces y finales de origen barbacoa en los nombres geográficos de la cuenca del Guayas correspondería no tanto al asentamiento y dispersión del reino Chono, cuanto al sustrato previo a su ocupación de la zona.

De muy diferente opinión es Espinoza Soriano, quien aventura la hipótesis de que la lengua de los Chonos no sería en realidad la cayapa-colorado de Jijón y Rivet, sino más bien "la misma lengua de los silvícolas de Aparia, pues Orellana comprendía ambos idiomas, lo que quiere decir que lo aprendió en Guayaquil" (Espinoza Soriano, 1988: 132). Y añade que alternativamente los chonos podrían haber sido emigrantes de Quijos "por cuanto en el siglo XVI a una de las parcialidades de Daule se le conocía con el nombre de Quixos-Daule" (1988: 132). Aparia fue uno de los principales poblados omaguas que visitó Orellana a orillas del Coca, al norte de la región de Quijos, en su viaje de descubrimiento del río Amazonas. De los omaguas nos han llegado un par de breves descripciones sobre sus costumbres y apariencia, que transcribimos a continuación por contener sorprendentes similitudes con algunos rasgos chonos (cf. supra):

"Llegaron, en fin, á tierra de gente de razón, que comían pan y vestían algodón" (López de Gómara, 1858: 243)

"Es la gente de este río bien pulida, bien agestada y dispuesta; vestidos de manta y camiseta de pincel, pintada de diferentes suertes y colores, las mujeres con ropas de las mismas pinturas; entre ellos había algunos que traían patenas de oro en los pechos, las mujeres orejeras y otras piezas en sus narices y gargantas" (Carvajal, 1894 [1546]: 433)

Al no disponer de gramáticas, vocabularios o listas de palabras para dicha lengua, la única forma de establecer una posible filiación genética entre el chono, por un lado, y las lenguas barbacoas o la lengua tupí de los Omaguas, por el otro, es la toponimia y la antroponimia. Serviría de mucho para igual propósito realizar una comparación de la evidencia arqueológica disponible para la cultura Milagro-Quevedo y la zona del Coca, sobre todo en su margen oriental.

En torno a la situación lingüística prehispánica de la costa ecuatoriana

Aún cuando en los párrafos anteriores nos hemos referido a las tres principales culturas de la Costa ecuatoriana antes de la conquista española, no podemos asumir que a cada una de ellas corresponda necesariamente una lengua específica. El escenario más posible en este sentido, sería uno donde varias lenguas o dialectos correspondieran a una cultura y que entre ellos predominara una variedad sobre las demás. De cualquier manera, los datos lingüísticos disponibles para la costa son tan escasos que impiden una afirmación categórica, si bien existan indicios que apuntan en ciertas direcciones. En esta medida resulta apresurado hablar de "la lengua de los chonos" o "la lengua de los huancavilcas", y es que la composición etnolingüística de la Costa ecuatoriana al momento de la conquista era más compleja de lo que supone una identificación de sus principales culturas. Por ejemplo, luego del análisis de una docena de fuentes, Jijón (1943: III-102s) identifica siete grupos étnicos en la costa del Ecuador: 1) los pueblos de marinos, que incluían los de la confederación de mercaderes (manteños), los huancavilcas y los puneños; 
2) los caraques o esmeraldeños; 3) los colimas (actuales awa); 4) los serranos, que incluían a los cayapas (actuales chachis) y a los colorados (actuales tsáchilas); 5) los chonos o indios del Daule; 6) los malabas; y 7) los yumbos. En la misma línea, un trabajo más reciente identifica para la costa norte del Ecuador (norte de Manabí y Esmeraldas) cerca de diez grupos étnicos ${ }^{13}$ (Palop, 1994: 140).

En base al análisis de fuentes arqueológicas, etnohistóricas y lingüísticas es posible elaborar un mapa etnolingüístico general de la Costa ecuatoriana (ver Anexos, Mapa 1). Pero aún entonces, nada nos asegura que a cada grupo corresponda una lengua específica. De hecho, las primeras relaciones geográficas de la costa ecuatoriana sugieren lo contrario. Así, la descripción anónima de la ciudad de Guayaquil en 1605 subraya la existencia de una gran variedad lingüística en el litoral del Ecuador. A continuación transcribo los pasajes relevantes a la composición lingüística imperante en la Costa a finales del siglo dieciséis:

"En cada pueblo [de indios del distrito de Guayaquil], y aun en algunos en cada parcialidad, hablan los indios lengua diferente, propia y antigua de aquél lugar; no usan lengua común entre todos, ni la del inga, ni otra. La que saben ya casi todos y corre en general, es la castellana";

"Los indios de esta tierra [distrito de Puerto Viejo] no convenían en una lengua general y común a todos: cada pueblo hablaba la suya diferente, lo cual era causa de discordia y guerras entre ellos: los indios marítimos se entienden todos entre sí, aunque la lengua que usan no es... (Ilegible). Dícese que conocían y distinguían los días de la semana con nombres particulares, y que tenían al domingo por el más solemne, y le llamaban tepipichinche, y que a sus hijos ponían nombre del día en que nacían";

"Las lenguas propias y antiguas de los moradores de este lugar [Charapoto] son diversas: los antiguos naturales hablan la suya; los de Tusagua, Conchipa y Toal otra, y los de Pasao no tienen lengua común sino es la castellana";

“Tenían estos 4 pueblos [Jaramijó, Camillos, Cama, Manta] lengua propia y común a ellos”;

"Saben la lengua castellana en general todos los indios de este lugar [Picuaza], y algunos cantan diestramente canto de órgano, pero solos dos dicen que había que supiesen leer, el cacique y otro";

"Tenían diversas lenguas [los de Jipijapa], cada parcialidad la suya: ahora hablan todos una que ha prevalecido, y más comúnmente hablan la castellana" (Anónimo, 1994: 18, 33, 43, 44, 46, 48).

Tres observaciones caben respecto a los pasajes anteriores. La primera y más evidente, es el avanzando proceso de castellanización de ciertas poblaciones (las del distrito de Guayaquil en general, y las de Jipijapa y Picuaza en el distrito de Portoviejo), proceso que en algunos casos concluyó con la desaparición de la lengua nativa (por ejemplo, en la población de Pasao, y a juzgar por el uso de 'tenían', también en los pueblos de Jaramijó, Camillos, Cama y Manta). La segunda es la diversidad de lenguas dentro de una misma zona (las lenguas de los distritos de Guayaquil y Portoviejo en general, y más específicamente las de las parcialidades de Charapoto, Tusagua, Conchipa y Toal, reducidas en el pueblo de Manta, así como las lenguas de las ocho parcialidades de Jipijapa). La tercera, finalmente, es la existencia de una comunión lingüística entre varias parcialidades, bien en su origen, bien como resultado del contacto lingüístico: en el primer caso, entre los "indios marítimos", que se entienden todos entre sí; en el segundo caso,

13 Sin contar dos - los Barbacoas y Sindaguas - que habrían ocupado el extremo meridional de la costa pacífica de la actual república del Colombia. 
entre las parcialidades de Jipijapa, donde para entonces había prevalecido una de las lenguas sobre las demás, la cual era hablada conjuntamente con el castellano.

Confirma la temprana castellanización de la costa el que ninguna de las tres relaciones geográficas de la provincia de Guayaquil de que disponemos para el siglo dieciocho - Montúfar y Fraso (1754), Anónimo (1772), Requena (1774) - mencione una lengua hablada por los indígenas que no sea el castellano. En realidad la única excepción es la mención que hace Requena de los habitantes de los pueblos de la Canoa y Tosagua, "[que] son zambos de indios y usan un dialecto particular diferente del inca; según las noticias que ellos mismos han conservado de sus antepasados, parece que naufragó en esta costa una embarcación con negros bozales, los que se mezclaron con las mujeres del país y de este modo formaron un idioma particular, muy extraño del que se habla en el Perú" (Requena, 1992 [1774]: 586). La lengua a la que se refiere Requena no puede ser otra que el esmeraldeño, lengua que Stevenson encontró en Esmeraldas, Río Verde y Atacames hacia 1808 y del cual J. M. Pallares recogió para Teodoro Wolf un vocabulario y glosas entre sus últimos hablantes hacia la década de 1870. Según Newson (1995), los zambos de Illescas se habrían asentado no sólo alrededor de la Bahía de San Mateo al norte, sino también en la región que se extiende hasta Coaque y Cabo Pasao, como resultado de su expansión hacia el sur y de la fundación y reubicación de reducciones por parte de los misioneros mercedarios en el siglo diecisiete.

Es muy probable que muchas de las lenguas de las que habla el autor anónimo de la relación de 1605 no fueran más que dialectos de una sola, con diferentes grados de inteligibilidad, pero que a oídos del relator resultasen lenguas distintas. Tal sería el caso de las lenguas habladas en las ocho parcialidades de Jipijapa, que al cabo de algunos años se redujeron a una, bien por nivelación dialectal (dialect leveling), bien por el predominio de un dialecto sobre los demás a cuenta de su mayor número de hablantes o de su mayor prestigio. De hecho, lo más probable es que en este caso se produjera una nivelación dialectal, en razón de haber sido congregados los indios de las ocho parcialidades en una sola reducción (San Lorenzo de Jipijapa).

En general, la situación lingüística antes y después de la conquista debió haber sido más complicada de lo que sugiere Jijón, para quien todas las hablas de la Costa desde la desembocadura del Mira se reducirían en una sola lengua, la que él llama "manabita, dividida en muchos dialectos" (Jijón y Caamaño, 1943: III-99). Jijón transcribe como sustento de su afirmación varias citas de cronistas como Oviedo o Cieza de León, en las cuales resalta un conjunto de rasgos de la cultura material e inmaterial de todos los indios de la Costa. Esta comunión de rasgos culturales, sin embargo, es para nosotros más el reflejo de la pertenencia a un área cultural compartida - el área septentrional andina occidental - que la existencia de una homogeneidad lingüística. El hecho de que existieron y existen en la provincia de Esmeraldas lenguas genéticamente distintas nos advierte contra cualquier generalización apresurada. En otras palabras, si la diversidad lingüística era considerable en la costa norte del Ecuador, la costa centro-sur no tiene por qué haber sido la excepción. Creemos que las palabras de Jijón, con todo lo probable que resultan a partir del análisis de las fuentes, deben ser matizadas tomando en cuenta siempre como criterio básico o regla práctica que a una cultura no necesariamente corresponde una lengua específica, o bien, que no existe una relación de equivalencia perfecta entre lengua y cultura. Recordemos unas palabras que pese a haber sido escritas hace noventa años no dejan de tener absoluta vigencia para el análisis de las culturas y de las lenguas. Al hablar sobre la relación esencialmente inestable y ambigua entre raza, lengua y cultura, Sapir insiste en que,

"los accidentes de la historia están reordenando constantemente las fronteras de las áreas culturales sin que borren necesariamente las divisiones existentes entre las lenguas" (Sapir 1921).

En los años que siguieron a la conquista, la dinámica demográfica de la Costa se vio convulsionada de maneras insospechadas. Los procesos de reagrupación de sectores de una misma población o incluso de diferentes poblaciones a través de reducciones, motivaron una 
restructuración sociopolítica de profundas consecuencias para el panorama lingüístico existente hasta entonces.

\section{La Costa del Ecuador después de la conquista española}

En toda la América indígena, el siglo dieciséis fue trágico y convulso. El exterminio que sufrieron decenas de miles de indígenas anticipó la extirpación de muchas de sus expresiones culturales y lingüísticas. En unos casos la prohibición de hablar el vernáculo fuera de la familia y la comunidad; en otros la imposición violenta de las llamadas lenguas generales a través de la evangelización; y aún en otros la desaparición física de sus hablantes - o su mimetización dentro del complejo sistema de castas coloniales - fueron factores que incidieron directamente en la muerte de centenares de lenguas indígenas desde los primeros años de la conquista. En la Costa ecuatoriana, con excepción de su parte septentrional, la población es exclusivamente hispanohablante, y lo fue desde muy temprano a juzgar por informes como la descripción anónima de 1605. Para entender las razones de tan temprana castellanización, así como otros posibles escenarios de los mencionados - la nivelación dialectal o la subsistencia de hablas nativas en algunos reductos alejados - es preciso explorar la reconstitución demográfica de los grupos aborígenes costeños desde inicios de la conquista, hasta finales del período colonial.

Evolución demográfica de la costa ecuatoriana (1532-1820)

De acuerdo con Newson, el índice de despoblamiento de la costa centro-sur en los primeros setenta años de conquista española se encuentra en el orden del 99 por ciento, "que, con excepción del Caribe, es uno de los más altos que se han calculado para una región del Nuevo Mundo $^{14 "}$ (Newson, 1995: 259). Al estudiar los cambios demográficos del Ecuador colonial, Newson sostiene que al momento de la conquista, la Costa representaba la tercera parte de la población total de lo que años después fue la Real Audiencia de Quito y que en la realidad estaba más densamente poblada de lo que se ha pensado hasta hoy - sobre todo en algunas áreas como la cuenca del Daule, donde existe abundante evidencia de prácticas agrícolas intensivas. Así, de un estimado de 370.230 habitantes al momento de la conquista, la población costeña se redujo a 3.530 a la fecha de la descripción anónima de Guayaquil (1605). Esto significa que en poco más de setenta años la población se redujo a menos de la centésima parte (Newson, 1995: 259). Pero eso no es todo. Fue precisamente el grupo étnico más numeroso - el chono, con una población de 302.260 habitantes al momento de la conquista - el que más vio reducida su población, llegando a 1.462 individuos poco antes de 1605. Las razones de esta estrepitosa caída fueron el hallarse en la zona de influencia inmediata del puerto de Guayaquil, que impuso sobre este grupo todo tipo de obligaciones tributarias y laborales, y el que dicha cercanía le volviera más proclive al contagio de enfermedades que entraban al continente por los barcos que atracaban cada año en el puerto. Pero también los huancavilcas (manteños) y punáes vieron diezmado su número por epidemias, exceso de trabajo, maltrato y guerras. La autora señala de especial virulencia las epidemias de sarampión, viruela y tifus que asolaron la Audiencia entre 1586 y 1591.

Sin embargo, las epidemias y la destrucción se hicieron sentir mucho antes de que la Costa empezara a ser colonizada, y fueron precisamente los habitantes de Manabí y la isla Puná quienes llevaron en ello la peor parte. Luego de la exploración de Bartolomé Ruiz en 1526, Pizarro desembarcó en 1531 en la isla Puná con 180 hombres y permaneció allí durante seis meses, con gran perjuicio de los indios, hasta que llegaron los refuerzos de Hernando de Soto, gracias a los cuales puede salvar la vida él y sus hombres y dispersar a la población nativa sobreviviente, gran 
parte de la cual se mudó enseguida a Balao para escapar de la masacre. La conmoción duraría hasta 1542, después de la muerte del obispo Valverde, cuando se ajustició a numerosos indios y caciques. Más desastrosa aún fue la suerte que corrieron en 1534 los habitantes de las zonas de Manta y Portoviejo en manos de la expedición de Alvarado, compuesta por 500 soldados, 2.500 indios y 200 esclavos negros, que sembraron el terror a lo largo de su recorrido desde el litoral costero hasta la Sierra; lo propio hicieron otros emisarios suyos en la zona de Santa Elena (Newson, 1995: 247s). Estos primeros contactos afectaron profundamente a la población nativa no sólo por la violencia y crueldad con que fueron abusados y asesinados numerosos indígenas, sino también por ser los primeros vectores de enfermedades epidémicas que se propagaron desde entonces en el litoral. Lo cierto es que a más de la sustancial disminución demográfica ocasionada por estos trágicos contactos, uno de sus principales efectos fue la dispersión de la población otrora concentrada y su huída al hinterland oriental. Quienes se arriesgaron a permanecer, serían reducidos enseguida en pueblos de indios para aprovechar al máximo su fuerza de trabajo.

La dinámica poblacional para la Costa septentrional (Esmeraldas y norte de Manabí) fue un tanto diferente. Su relativa lejanía de la costa centro-sur de Manabí y de la ciudad de Guayaquil, lugares donde atracaban embarcaciones bien para aprovisionarse de vituallas o entregar mercadería para el interior, bien para desembarcar soldados, civiles o esclavos, hizo que el impacto de las epidemias y las imposiciones tributarias fuera mucho menor. De hecho, prácticamente no se crearon encomiendas en la provincia durante el siglo dieciséis, y sólo en el diecisiete se logró fundar dos reducciones con los zambos de Illescas. Pese a la supuesta existencia de esmeraldas, la verdad es que nunca hubo para los españoles una población importante en la costa norte que hiciera rentable la creación de reducciones para extraer su fuerza de trabajo. Dos expediciones organizadas con el propósito de pacificar la provincia de Esmeraldas y el interior septentrional de Manabí a fin de repartir y encomendar a los indios que allí se encontraran, terminaron en fracaso rotundo: una fue la expedición de Andrés Contero (1568), otra, la de Carranza (1569). Ambas no sólo buscaban la llamada pacificación, sino también la fundación de poblaciones españolas en la zona y la apertura de un eventual puerto de la magnitud e importancia de Guayaquil, para arrebatarle a Quito su control sobre esta parte del litoral. El índice de despoblamiento en la costa norte fue del índice del 71 por ciento, menor que en la costa centro-sur pero aún bastante alto (Newson, 1995: 267).

Otro de los factores que moldearon la demografía de la zona, fue la presencia africana a raíz de la zozobra de un barco negrero frente a las costas de Portete en 1553. Los esclavos sobrevivientes se adentraron en la costa y sometieron a los indios campaces; luego se casaron con sus mujeres y, cuando aumentaron en número, extendieron su dominio sobre otros pueblos indígenas de la zona mediante una serie de victorias armadas al mando de Alonso de Illescas. Tres fueron las consecuencias a corto, mediano y largo plazo de esta accidental penetración del elemento afro en Esmeraldas: 1) la formación de un número cada vez más grande de zambos que extendieron su zona de influencia en el litoral costero desde la Bahía de San Mateo hasta cerca de Cabo Pasao y en el hinterland hasta las cabeceras del Daule y la confluencia del Quinindé con el Guayabamba; 2) la retirada tierra adentro por parte de varias poblaciones indígenas que habitaban las costas y la reorganización general del espacio étnico de la provincia; y 3) el sometimiento, en algunos casos en forma de esclavitud, de poblaciones indígenas en manos de los zambos. Una cuarta consecuencia habría sido la inmunidad hereditaria perpetuada en las poblaciones locales a través de la mezcla con el elemento afro (Newson, 1995: 266).

La consecuencia inmediata del descenso demográfico fue, para los españoles, la falta de mano de obra para sus obras civiles y servicios personales. El primer documento disponible que da razón de los indios tributarios en la provincia de Guayaquil data de 1577. Si la fundación de Guayaquil se consolida apenas en 1547, esto significa que la reducción de las diferentes parcialidades indígenas de la provincia se desarrolló en aproximadamente veinte años. Es posible que la congregación no hubiera dado mucho que hacer a los conquistadores en razón del entonces ya reducido número de indígenas, si bien la gran extensión de territorio en que se hallaban 
dispersos debió haber ofrecido más de un problema. Con la congregación de parcialidades en pueblos de indios, se les reconoció a éstos "asientos territoriales", que en el caso de la Península de Santa Elena datan de la década de 1560 (Álvarez, 2002: 15). Como atestiguan los pasajes de la relación anónima de 1605, fecha para la cual los pueblos de indios llevaban al menos cuatro décadas de existencia, habían sido congregados en reducciones, en unos casos, indios de la misma lengua o al menos - así podemos suponer - de dialectos mutuamente inteligibles, pero en otros, los indios de un mismo pueblo pertenecían a parcialidades de distinto origen lingüístico. El conocimiento de situaciones similares en otros contextos coloniales alrededor del mundo nos permite pensar que, en el primer caso, la lengua se conservó con cierta nivelación dialectal o con el predominio de un dialecto sobre los demás, mientras que en el segundo, fue el castellano la lengua utilizada para la comunicación interétnica, pues como admite la relación de 1605 no había una lengua común que usaran los indios, ni el quichua ni otra general. Tampoco es descabellado suponer que se haya producido, aunque fuera por poco tiempo, el nacimiento de un pidgin entre los diferentes hablantes, si bien esta probabilidad habría sido más alta si éstos nunca hubieran estado en contacto previo, cosa poco probable debido a los intensos contactos entre diferentes pueblos del litoral costero y su hinterland dentro de la sociedad manteño-huancavilca. Es más probable que alguna de las lenguas prehispánicas haya sobrevivido - como sobrevivió el esmeraldeño - en zonas del interior de la costa donde no lograron penetrar los españoles; lamentablemente es imposible asegurarlo al carecer de informes al respecto.

Aunque la formación de centros nucleados pudo haber aumentado la probabilidad de epidemias o incluso pandemias como las de la década de 1580, también es cierto que por la escasa presencia de encomenderos y otros españoles en los pueblos de indios, sus habitantes estuvieran de alguna manera menos expuestos a fuentes de contagio. La absoluta mayoría de encomenderos españoles residía en Guayaquil, Paita o incluso Lima (Fauria, 1995) y algunos de sus hijos con mujeres indígenas de las reducciones permanecían en ellas y reclamaban el estatus de mestizos para evitar los tributos (Álvarez, 2002: 15). Además, algunos pueblos de indios, sobre todo los más alejados de Guayaquil, estaban prácticamente desatendidos por los párrocos, como insiste el prolijo informe de Requena de 1774 para los partidos de Ojiva (Babahoyo) y Santa Elena:

\footnotetext{
“Así como faltan los jueces, también faltan los párrocos. Todo este partido no tiene más que un cura con residencia ordinaria en Babahoyo [...] El cura regularmente no va a estos pueblos [Babahoyo, Ojiva, Puebloviejo, Ventanas, Palmar, Chilintomo, Caracol, la Isla] sino en el tiempo destinado para fiestas [...] Donde están en el mayor abandono de párrocos es en las Ventanas: distantes allí del curato de Angamarca más de 16 leguas y otro tanto del de Babahoyo, no participan las haciendas de aquellas inmediaciones, ni los indios jíbaros del Zapotal que están en las montañas, por ninguna parte de auxilio espiritual" (Requena 1992 [1774]: 536).

“Todos estos pueblos [del partido de Santa Elena], tan separados como se ha visto unos de otros, están servidos por un solo cura doctrinero [...] tal vez para tener algunos días con seguridad al párroco, pues ordinariamente hace la residencia en uno, dejando a todos los demás sin el pasto espiritual ni auxilios postrimeros que tanto necesita el carácter particular de estos indios, dados a las supersticiones, por lo cual obliga esto, más que lo disperso de los pueblos, a la asistencia personal de un sacerdote en cada uno [...]" (Requena 1992 [1774]: 572).
}

Estas informaciones nos hacen pensar en la posibilidad de que alguna de las lenguas indígenas prehispánicas del litoral haya podido sobrevivir hasta bien entrado del siglo dieciocho, sobre todo en los últimos reductos étnicos cerca del piedemonte andino occidental. De hecho, los que Requena llama "indios jíbaros de Zapotal” no eran sino una parcialidad tsáchila asentada en la zona.

Con estos antecedentes, es preciso subrayar que si bien el proceso de castellanización fue mucho más rápido en la Costa en general que en otras regiones, lo más probable es que no haya 
sido una castellanización uniforme y con la misma intensidad en todos los sectores. No obstante, la ausencia de indicadores lingüísticos para evaluar esta propuesta hace que se mantenga en el plano de lo hipotético. Sea como fuere, lo cierto es que la lejanía de muchos partidos y la dispersión de sus poblaciones se convirtieron con el paso del tiempo, en una ventaja de la cual supieron sacar buen provecho los pueblos de indios, quienes obtuvieron mayor independencia en sus decisiones productivas y reproductivas y utilizaron la base territorial de dichos pueblos como matriz de su recuperación socioeconómica y cultural. En palabras de Álvarez,

"La Reducciones y las tierras del Común hay que reconocer también que fueron refuncionalizadas por los grupos indígenas. Éstos las usaron como mecanismos de cohesión a la diversidad de grupos concentrados. Sirvieron para el fortalecimiento de nuevas formas de organización, el adiestramiento en el manejo de los nuevos códigos sociales y legales, y el aprovechamiento económico que podía producir la articulación del sistema mercantil” (Álvarez, 2002: 15).

Como señala la misma autora, los pueblos de indios se engastaron en la economía colonial a partir de las funciones productivas que cumplían antes de la Conquista. Así, por ejemplo, los indios chonos fueron utilizados en la navegación fluvial por ser expertos en ella, como los de la Punta de Santa Elena lo fueron en la provisión de sal, copal y pescado, pero también como vigías costeros y ayudantes en el aprovisionamiento de barcos que atracaban frente a sus costas. Más aún, teniendo como centro administrativo y político la reducción, los indígenas pudieron expandir su base territorial de manera organizada y sistemática, protegiéndose al mismo tiempo de las invasiones perpetradas por españoles y mestizos y reclamando una vinculación inmemorial con la tierra de sus antepasados ${ }^{15}$. Estos desarrollos ocurrieron contemporáneamente a una notable recuperación demográfica, la misma que se concentró en la Península de Santa Elena y la actual provincia de Manabí. De acuerdo con Hamerly,

"No se sabe cuándo empezó a recuperarse la población indígena costeña del impacto demográfico de la conquista. Sospechamos que los indios del litoral dejaron de declinar hacia fines del siglo XVII, pasaron un período de convalecencia hasta mediados del siglo XVIII, y sólo entonces comenzaron a multiplicarse" (Hamerly, 1973: 73).

El período de convalecencia al que se refiere Hamerly sería la línea divisoria entre la etapa de encomiendas y reducciones y la etapa de las "Grandes Comunidades Étnicas" que propone Álvarez para la Península de Santa Elena ${ }^{16}$. Estas grandes comunidades serían el resultado de la recomposición étnica de las antiguas parcialidades y pueblos de indios y constituirían la matriz de reproducción biológica y cultural de una población indígena reconstituida:

15 Tres fuentes que proporcionan amplia evidencia de esta afirmación son los siguientes, para los partidos de Daule, Santa Elena y Babahoyo respectivamente: 1) los Testimonios y Memoriales sobre el Señorío de Daule en los términos de la ciudad de Guayaquil, años 1599-1600, publicados, aunque de forma fragmentaria, por Espinoza Soriano (1988: |176-191); 2) el Libro de Inscripción de Sacachún, sitio adquirido por los indios de Chanduy en la Provincia del Guayas (copia transcrita en posesión del autor); y el expediente titulado "Pedro Chaparro y Manuela Tomalá, caciques principales del pueblo de Baba, contra Marcos Avellán sobre la nulidad de una compra hecha a Manuela Tomalá de una parte del sitio de Carrizal” (AHG, EP/J 6032 [1806]).

16 Álvarez identifica seis para la provincial de Guayaquil: Colonches, Punteños, Chanduyes, Chongones, Puneños, Morreños (Álvarez 2002: 21). Aunque compartimos con la autora su propuesta sobre la consolidación de las "grandes comunidades étnicas" - el mismo Requena identifica a los chanduis en su relación de 1774 como una comunidad étnica claramente diferenciada - nos parece que la imagen de absoluta cohesión y armonía entre dichas comunidades es más asumida que demostrada. El expediente titulado "Litigio por el pueblo de Colonche en el partido de Santa Elena sobre el despojo que le infieren los naturales vecinos del pueblo de la Punta en sus sitios de la Cueva y Carrizal ..." (AHG, EP/1153 [1810-13]) demuestra con claridad que las comunidades que propone Álvarez constituían su identidad étnica primero hacia adentro y que sólo frente a enemigos externos que afectaban sus recursos o supervivencia a nivel regional ofrecían una respuesta común, la cual, sin embargo, no implicaba necesariamente una supuesta identidad "huancavilca". Al respecto véase, por ejemplo, el expediente "Indios de Chanduy y Colonche para que se les exima del servicio de vigías..." (AHG EP/J 2459 [1803]). 


\begin{abstract}
"Hubo un incremento poblacional de cerca del $450 \%$ en el litoral central, poblado de indios y mestizos. La población de la Provincia de Manabí y del cantón de Santa Elena evidentemente aumentó de [8.334] en 1765 a [37.144] en 1839/1840. En este sector y entre estas fechas tuvo lugar aparentemente la única revolución demográfica del Ecuador antes del siglo XX. Esta explosión sólo puede explicarse por un balance favorable, consistente y/o a largo plazo, entre una alta tasa de mortalidad y una aún más alta tasa de natalidad" (Hamerly, 1973: 70).
\end{abstract}

El crecimiento demográfico para los partidos interiores de la provincia de Guayaquil fue menor y menos sostenido. La población del interior creció un $250 \%$ entre 1765 (4.297) y 1825 (10.367). En este caso, sin embargo, el crecimiento poblacional se debió a la inmigración de indios y mestizos serranos que se asentaron en las grandes haciendas cacaoteras durante el boom de la pepa de oro a finales del siglo dieciocho. Aunque disponemos de pocos datos para la provincia de El Oro, es altamente probable que se haya producido un desarrollo demográfico similar.

En este punto es preciso señalar que las cifras de población de Santa Elena y Manabí incluyen a indios y mestizos. La razón se halla en que la adscripción entre uno y otro grupo era variable y obedecía a criterios de índole estratégica con relación a los recursos y las obligaciones tributarias. Al mismo tiempo, la presencia del componente afro en la población costeña, si bien importante a lo largo del siglo diecisiete y principios del dieciocho, sufrió una reducción sostenida desde mediados de 1700 pues su fuerza de trabajo fue reemplazada por las mismas comunidades indígenas de la Costa, y desde finales del siglo dieciocho, por la creciente migración de indios serranos, sobre todo en los partidos del interior y en los alrededores de la ciudad de Guayaquil. En general, la mezcla racial con el componente afro fue relativamente pequeña en la parte occidental de la costa centro-sur. La excepción fue Manabí - y posiblemente la cuenca baja del Daule - en cuya parte norte existía hasta el siglo dieciocho un componente afro resultante de la mezcla entre los negros de Illescas y los indios de la región (cf. supra). Al respecto Hamerly sostiene que esta mezcla fue importante en el sector oriental del distrito de Portoviejo y dio origen al pueblo montubio (Hamerly, 1973: 74).

Comparada con la costa centro-sur, la provincia de Esmeraldas muestra una tendencia contraria en la segunda mitad del siglo dieciocho y en la primera del diecinueve (Hamerly, 1973: $80)$, pues se mantiene prácticamente estática desde $1780(2.479)$ hasta $1825(2.352)$ y se duplica solamente entre este último año y 1840 (5.229). La población nativa en este caso permaneció mayoritariamente dispersa, a veces en lugares inaccesibles por la falta de vías de acceso. Esto sugiere que las cifras anteriores representan apenas una pequeña parte de la población total de la provincia y que las distintas parcialidades étnicas identificadas en la costa norte se mantuvieron en alguna medida fuera de los cambios demográficos y las transformaciones socioeconómicas que tuvieron lugar desde el siglo dieciséis hasta los primeros años del diecinueve.

Lo dicho hasta sirve como marco para entender los cambios en la composición lingüística de la costa ecuatoriana a raíz de las transformaciones demográficas y la reorganización socioeconómica de la población nativa desde los primeros años de la conquista hasta finales de la Colonia (ver Anexos, Mapa 2). Sólo una comprensión cabal de la dinámica poblacional de la Costa puede ayudarnos a comprender mejor el por qué de su castellanización, temprana aunque posiblemente parcial hasta el siglo dieciocho, y el por qué de la supervivencia de algunas lenguas indígenas hasta el día de hoy. Este trasfondo, con la breve descripción que sigue de las fuentes y los estudios lingüísticos sobre las lenguas prehispánicas de la costa, pretende ser el punto de partida para el análisis evaluación de los datos toponímicos y antroponímicos y los deslindes lingüísticos que son posibles a partir de ellos, tal como nos proponemos en la partes segunda y tercera de esta investigación. 


\section{Fuentes para el estudio de las lenguas prehispánicas de la costa ecuatoriana}

Quizá por la temprana castellanización del litoral, por la idea de que los componentes étnicos de la costa centro-sur desaparecieron para diluirse en la corriente del mestizaje, y por qué no, por la escasa evidencia lingüística, los estudios sobre las lenguas prehispánicas de la Costa son muy pocos y se han basado exclusivamente en las únicas fuentes disponibles, las de la toponimia y la antroponimia. Esta situación, sin embargo, no es excepcional, pues cosa semejante ocurre cuando se procura desentrañar la naturaleza de las lenguas pre-kichwas de la Sierra.

La excepción a lo dicho anteriormente son las lenguas de la costa septentrional y el piedemonte occidental de los Andes. Con excepción de la extinta lengua esmeraldeña, las demás son habladas todavía en la actualidad, y lo fueron en el pasado por distintos grupos étnicos (Jijón, 1943: III-102s): el tsa'fiki, lengua de los actuales tsáchilas, habría sido hablado por los llamados campaces; el cha'palaa, lengua de los chachis, habría sido hablada por los niguas; y el awapit, lengua de los awa, habría estado en boca de los colimas. Sobre estas lenguas existe abundante material lingüístico, incluyendo no sólo listas de palabras, vocabularios y diccionarios recogidos y producidos desde principios del siglo diecinueve hasta el día de hoy, sino también gramáticas, análisis de algún nivel de la estructura lingüística, e incluso colecciones de literatura oral con sus respectivas versiones castellanas. Por esta razón no hablaremos aquí de las fuentes o los estudios relacionados con estas lenguas. En su lugar referimos al lector a la extensa recopilación bibliográfica preparada por Alain Fabre $(2005)^{17}$, la misma que puede ser consultada en línea bajo la entrada "Barbacoa", que es el nombre de la familia lingüística a la que pertenecen.

El primer sínodo diocesano quiteño celebrado por el Obispo López de Solís en 1583 ordenó la confección de catecismos para seis lenguas que se hablaban en los Andes septentrionales. El pasaje relevante del capítulo tercero reza así:

"Por la expiriencia nos consta que en nuestro obispado ay diversidad de lenguas, que no tienen, ni hablan la del Cuzco, ni la aymara, y que, para que no carescan de la doctrina cristiana, es necesario hazer traduzir el cathecismo y confesonario en las propias lenguas; por tanto, conformandonos con lo dispuesto en el conçilio provinçial ultimo, abiendonos ynformado de las mejores lenguas que podrian hazer esto, nos a pareçido cometer este trabajo y cuidado a Alonso Nuñez de san Pedro y a Alonso Ruiz para la lengua de los llanos y tallana; y a Gavriel de Minaya, presbitero, para la lengua cañar y purguai; y a fray Francisco de Xerez y a Fray Alonso de Xerez, de la Orden de la Merced, para la lengua de los Pastos; y a Andres Moreno de Çúñiga y N. Diego Bermudez, presviteros, para la lengua de quillaçinga, a los quales encargamos lo hagan con todo cuydado y brevedad; pues dello sera nuestro Señor servido, y de nuestra parthe se lo gratificaremos, y hechos los dichos catesismos, los traygan o envíen ante nos, para que vistos y aprovados, puedan usar dellos" (Carmona, 1996 [1583]: 72-73).

No sabemos si los catecismos se llegaron a escribir, pues hasta la fecha no se ha encontrado ninguno de ellos. Lo cierto es que, de existir, serían la única evidencia de las lenguas prehispánicas que se hablaron en el obispado de Quito ${ }^{18}$. Para el caso que nos ocupa, nos interesan dos en particular, la llamada lengua de los llanos y la atallana. De ésta sabemos que era hablada en la costa norte del Perú y su hinterland, alrededor de la región de Paita, pero que probablemente comprendía varios dialectos con diferentes grados de inteligibilidad (Colán, Catacaos y Sechura $)^{19}$. Al respecto, un cronista señala que "en el río que llaman de la Piura [...] hay una

17 Alain Fabre. Diccionario etnolingüístico y guía bibliográfica de los pueblos indígenas sudamericanos.

18 Carlos Arrízabalaga sostiene, de manera bien fundamentada en nuestra opinión, que el catecismo tallán nunca llegó a escribirse, como es posible que tampoco se preparara aquél de la lengua de los llanos. Al respecto véase ¿Un catecismo tallán? Evangelización en lenguas indigenas en Piura a finales del siglo XVI (Arrizabalaga 2008).

19 Más sobre estas lenguas se dirá en la sección dedicada a explorar posibles relaciones filogenéticas con las habladas en la costa centro-sur de nuestro país. 
Lengua, e llámase tallanes" (Oviedo, 1941: II-222-231). De la lengua de los llanos, por el contrario, no se ha identificado hasta hoy ninguna otra referencia, por lo que su identidad sigue siendo desconocida. Al contrario, existen varias menciones en fuentes etnohistóricas sobre los "indios de los llanos", de quienes, por ejemplo, Salinas de Loyola dice que "van en disminución, por ser tierra enferma, y por haber sido el paso de todos los españoles que iban al Pirú" (citado en Jiménez de la Espada, 1965, II: 42). Por la lectura de cronistas como Cieza de León (1922 [1553]: 147, 202, 205) nos percatamos que el término "llanos" puede referirse tanto a las tierras bajas de la costa centro-sur de nuestro país como al desierto que se extiende desde Tumbes hasta Trujillo en el Perú. De este modo, la "lengua de los llanos" podría ser bien la lengua de los manteño-huancavilcas, o bien cualquiera de las habladas en el extremo noroeste del Perú. Sin embargo, no vemos razonable esta última alternativa, porque el sínodo ya se refiere a las lenguas tallanes, habladas precisamente en la costa norte peruana. De acuerdo con Jijón, la lengua de los llanos no es otra que la lengua que la 'manabita', atomizada en muchos dialectos (Jijón, 1941: II99), incluyendo el huancavilca y el puná. Sin embargo, el mismo autor señala más adelante que la "lengua de los llanos" es la misma que la lengua de los "pueblos de marinos" que mencionan las crónicas (1941: 395). No comparte la misma opinión Paz y Miño (1961), que en su estudio de clasificación de las lenguas aborígenes del Ecuador propone una "familia lingüística atallana", que tendría como dialectos el wankawilka, el amay, el puná y el túnbe [sic]. Separa de esta familia a la lengua manteña, que no la asocia con ninguna otra de la Costa (Paz y Miño, 1961: 12). Nuestra opinión sobre este punto concuerda con la de Jijón, para quien la lengua de los llanos es una muy diferente de la lengua tallán.

Las fuentes para el estudio de la lengua de los llanos y la atallana son, por decir lo menos, escasas. Para esta última disponemos de un precioso vocabulario de cuarenta palabras en sus dos principales dialectos (Colán y Catacaos), recogido junto al de otras seis lenguas aborígenes por el obispo de Trujillo, Baltasar Jaime Martínez Compañón, entre 1782 y 1784. No disponemos de ninguna lista de palabras para la lengua de los llanos.

En la recolección toponímica ambas lenguas han corrido con mejor suerte, pues existen no sólo listas de nombres geográficos sino también varios estudios, unos más recientes y exactos que otros, pero todos valiosos para determinar cuál habría sido su perfil e indagar su posible filiación con otras lenguas amerindias de la región. Para las lenguas tallanes disponemos de una extensa colección toponímica y antroponímica realizada por Ramos Cabredo (1950). Una importante colección de nombres geográficos de la costa norte del Perú y su comparación con topónimos de los Andes septentrionales la encontramos en Jijón (1940: I-422-454). El estudio más comprensivo de las lenguas de la costa norte peruana, incluyendo las tallanes de Colán y Catacaos, se lo debemos a Torero $(1986,1989,2002)$. Para deslindar las lenguas prehispánicas de la costa norte y la sierra norte peruana Torero utilizó las cartas geográficas levantadas por el Instituto Geográfico Nacional del Perú, monografías regionales y planos de municipalidades. Todas estas fuentes también existen para el Ecuador y resultan valiosas en el cotejo, ampliación y verificación de los datos toponímicos y antroponímicos. Nos hemos referido con algún detenimiento a la lengua tallana de la región de Tumbes y Paita porque sabemos que los indios de Tumbes compartían con los de la costa centro-sur del Ecuador rasgos culturales como resultado de la pertenencia a la misma sub-área cultural ${ }^{20}$, lo que hace probable a su vez un alto grado de comunión lingüística.

Las fuentes para el estudio de la "lengua de los llanos", asumiendo su equivalencia bien con la lengua de la sociedad manteño-huancavilca, bien con la lengua de la liga de mercaderes de la

20 Lo curioso es que, por ejemplo, Oviedo (1955 IV: 222) refiere que los indios de Tumbes y los de Puná llevaban prácticamente la misma indumentaria, aunque otros informes aseguran que los de Tumbes y los de la Puná estaban en un permanente estado de guerra. Al respecto véase la Breve Historia de Piura, de Reynaldo Moya Espinosa, que en la sección séptima del capítulo XI de su tomo primero, relata las batallas entre Tumbes y la Isla Puná. 
Costa, están compiladas en el monumental estudio de Jijón y Caamaño, El Ecuador Interandino y Occidental antes de la Conquista Castellana (1940-1945). Son de especial interés las fuentes que contienen los capítulos XXII (II, 398-414), XXIV (II, 420-423), y XXVIII, secciones 3 y 7 (III, 141-145, 176-180). Añádase toda la toponimia y antroponimia de origen tsáchila y chachi que Jijón identifica en los capítulos que dedica a cada una de estas lenguas en el primer volumen de su obra. Obra importante que compila el material de Jijón y otras fuentes es el hoy casi olvidado Diccionario Toponímico de Paz y Miño, compuesto por 10.196 entradas con su respectiva explicación, segmentación y, en muchos casos, ubicación geográfica (Paz y Miño, 1961-64). Numerosa información toponímica georeferenciada se encuentra igualmente en los 12 tomos del Índice Toponímico de la República del Ecuador (1972-8), publicado por el Instituto Geográfico Militar, que al momento se encuentra actualizando su base de datos con información levantada in situ para crear y difundir en línea la Base de Datos de Nombres Toponímicos (IGM, 2009: 5ss). Estamos seguros de que esta base de datos rectificará errores de omisión y distorsión en la toponimia de las cartas publicadas (1:50.000 y 1:25.000), los mismos que impiden la correcta identificación de las toponimias locales.

Ocurre con mucha frecuencia que la toponimia originaria de un lugar ha desaparecido o se ha castellanizado, razón por la cual no se consigna en cartas geográficas recientes (al menos del siglo veinte), aunque a menudo se conserva en la memoria colectiva y en fuentes históricas de primera mano que reposan en archivos de Guayaquil y Quito y en los de poblaciones menores, sobre todo en cabeceras parroquiales que fueron en su momento pueblos de indios, como Colonche en la Península de Santa Elena. También los registros de la propiedad guardan valiosa información de carácter toponímico (Álvarez, 2002: 4-41). Sobre la necesidad de incorporar estas fuentes a la investigación se tratará en la siguiente sección.

Los estudios de deslinde lingüístico que realiza Jijón para la costa del Ecuador en base al análisis de topónimos y antropónimos son dos. El primero, de carácter provisional, es su extenso artículo "Contribución al conocimiento de las lenguas indígenas que se hablaron en el Ecuador Interandino y Occidental con anterioridad a la Conquista Española" (Jijón, 1919). En dicho estudio se deslindan, a más de la zona de influencia del cayapa y el colorado, otras dos zonas lingüísticas de la Costa: la de la lengua esmeraldeña, para la cual se identifican las bases chich- y chiv- y las finales -le, -ja/-je, -de, -gue (55-63); y la de la lengua manabita o manteña, donde se aíslan la base chon- y las finales -tó, -ao, -ri y -li (63-64). De especial importancia para el análisis posterior de estos elementos morfológicos y el establecimiento de relaciones con otras lenguas del área septentrional andina occidental es la sección oncena del estudio antes mencionado, donde se identifica onomástica de origen mochica, sobre todo en la Costa y en la Sierra centrosur del Ecuador, específicamente en las zonas puruhá y cañari. El artículo de Jijón de 1919 fue la base para su obra principal, El Ecuador Interandino y Occidental (1940-45). En el capítulo titulado Ojeada general sobre la composición étnica de la Costa ecuatoriana (1941: II-70-103), Jijón realiza un estudio prolijo de las fuentes etnohistóricas y los conocimientos arqueológicos obtenidos hasta entonces para la Costa ecuatoriana. Complementa este capítulo otro titulado Los pueblos de marinos (1941: II-385-397). En base a su análisis de bases y finales de más de 1.000 voces toponímicas y antroponímicas, Jijón propone que,

"sin excluir la probabilidad de que en ciertos puntos del litoral hubiese enclaves de gentes de lenguas distintas, las usadas desde la desembocadura del Mira hasta Trujillo fueron: A) la manabita, dividida en muchos dialectos; B) la tallana, en Piura; C) la mochica, también dividida en dialectos, más al Sur (Jijón, 1941: II-99).

Con esto las lenguas del Litoral se reducirían a una, la manteño-huancavilca, excluyendo, claro está, otras identificadas por el mismo autor para el interior, como la lengua de los campaces y la de los colimas. A partir de allí el autor extiende sus comparaciones con otras lenguas de la costa norte peruana, sobre todo el mochica, cuya asociación ya había sugerido en 1919, para 
plantear finalmente un estrecho parentesco entre la lengua manteño-huancavilca de la costa, la cañari y la puruhá de la sierra, y la mochica del septentrión peruano occidental.

\begin{abstract}
"Mas no pararon aquí los resultados de nuestro estudio, pues bien pronto advertimos que nombres de tipo Puruhá-Cañari-Manabita-Guancavilca ocurrían también en la provincia ecuatoriana de Loja y en los departamentos de Cajamarca, Piura, Lambayeque, La Libertad, parte del de Loreto, en el de Anchash, Huánuco, Lima y Junín, en donde no era ya posible dudar de su origen mochica o yunga, con lo que el segundo de nuestros grupos de 1919 venía a quedar identificado no sólo en la forma, sino en el origen con el primero, tercero y cuarto.
\end{abstract}

Para entonces ya el doctor Max Uhle, sin tener conocimiento alguno de los resultados a que habíamos llegado, basándose en la traducción que de voces cañaris dan las Relaciones Geográficas de Indias, sostenía que el cañari era una variedad del mochicha, y antes don Otto von Buchwald, mediante etimologías valiosas, probaba que el mochica se había hablado en el Guayas" (Jijón, 1941: 396-97)

Hoy en día la propuesta de Jijón es generalmente rechazada, habiéndose propuesto en su lugar un origen barbacoa para lenguas como el puruhá o el cañari en base a una serie de elementos que apuntan a un origen común (Adelaar y Muysken, 2004: 395), pero sin mención del lugar que ocuparía la lengua manteña con respecto a las demás. Se requiere una nueva evaluación de los datos presentados por Jijón antes de descartar cualquier relación filogenética de las lenguas en cuestión. Como lo han demostrado varias investigaciones arqueológicas, desde el período de Desarrollo Regional existió una estrecha relación comercial y cultural entre el país puruhá y el cañari, por un lado, y las costas de Manabí y Guayas, por el otro.

"Por otra parte, la evidencia arqueológica acumulada desde el Período Formativo sugiere una fuertísima interacción entre esta región [Cañar, Azuay y Loja] y la costa de Manabí y Guayas. [...] La aparición de estas puntas de proyectil bifaciales, cuyo estilo es tradicional en las poblaciones que poblaron Cañar y Azuay desde épocas pre cerámicas, sugiere que los portadores de estas puntas de lanzas en la Península de Santa Elena tenían fuertes vínculos con esa región, o que provenían de ella" (Marcos, 1995: 113).

La propuesta de Jijón es parte de una clasificación más ambiciosa, según la cual todas las lenguas del noroccidente de América del Sur y la sección meridional de América Central formarían el phylum Macro-Chibcha. Quizás por ser la más inclusiva de todas las presentadas hasta entonces, la propuesta de Jijón fue recibida con escepticismo, aun cuando más tarde se hicieran propuestas más comprensivas. Por ejemplo, ya a mediados de los años cincuenta el lingüista norteamericano Joseph Greenberg propuso clasificar el mochica dentro del subgrupo paez del macro-chibcha y otras lenguas yungas como el tallán dentro del subgrupo andino del grupo andino-ecuatorial (Greenberg, 1956). Años después (1987) el mismo autor seguía clasificando el mochica dentro del subgrupo paez del grupo chibcha-paez, pero reubicaba el tallán (catacao) en una rama septentrional del grupo andino (Adelaar y Muysken, 2004: 44)21.

Aunque en varios casos resulta cierta la acusación que se hace a Jijón de interpretar antojadizamente el método lingüístico-comparativo a partir de una aceptación de equivalencias sistemáticas entre sonidos fonéticamente no relacionados (Adelaar y Muysken, 2004: 37), con la consiguiente segmentación incorrecta de la morfología de los topónimos (Torero, 2002: 234), no es posible descartar su propuesta de una filiación mochica sin una nueva evaluación de los datos para la Costa ecuatoriana. El mochica ha sido asociado con la familia lingüística

21 Para visualizar mejor estas clasificaciones sugerimos al lector consultar el Amerind Etymological Dictionary (Greenberg y Ruhlen 2007), obra valiosa que recoge diversas fuentes de manera comparativa, donde se pueden rastrear voces tallanes con otras de lenguas clasificadas dentro del mismo subgrupo. 
maya de Mesoamérica (Stark, 1968; 1972), hipótesis apoyada a menudo en investigaciones arqueológicas y en la idea del comercio a larga distancia (Marcos, 1995: 117ss), sin ser aceptada completamente por la comunidad científica. Aunque no excluimos relaciones lejanas dentro o fuera del continente, estamos convencidos de que se deben probar primero relaciones filogenéticas dentro de Sudamérica, específicamente dentro del Área Septentrional Andina. Al respecto sería interesante, por ejemplo, explorar la costa del Perú y rastrear vínculos con las lenguas 'pescadoras' como el quingnam, o bien la de Chile en busca de relaciones con lenguas como el kawésqar, que a propósito se conoce también desde la Colonia como 'chono'.

Una última mención merece la lengua esmeraldeña, que Jijón asocia con los antiguos habitantes de la zona de Bahía de Caráquez y Paz y Miño con un grupo diferente ${ }^{22}$. Las principales fuentes disponibles para su estudio son dos: 1) las pocas palabras que consigna Stevenson en su relato de viaje por la región de Esmeraldas-Atacames en 1808; y 2) el vocabulario y las glosas publicados parcialmente por Wolf en su Geografía y Geología del Ecuador (1892: 528) y en toda su extensión por Seler (1902: 49-64) y Jijón y Caamaño (1941: II-424-539), precedidos de sendos estudios introductorios y análisis morfosintácticos de tipo comparativo. No existe a la fecha consenso sobre la relación genética de esta lengua con otras conocidas, aunque desde el primer momento se han sugerido vínculos con el pumé, lengua aislada del estado de Yapuré en Venezuela (Seler, 1902: 62), y con el Yurimangui, lengua que se hablaba cerca de la ciudad colombiana de Cali (Rivet, 1942: 55). Por su parte, Jijón considera el esmeraldeño como de origen paleo-chibcha (Jijón, 1945 V: 477). Este autor encuentra varios topónimos de posible origen esmeraldeño dispersos en Manabí y Santo Domingo de los Colorados, territorio propio de las lenguas barbacoas. Un estudio reciente (Adelaar, 2005: 241) confirmaría la asociación de Rivet con el yarumangui colombiano, aunque la evidencia no es concluyente.

Se requiere un nuevo estudio de los datos a fin de dar al esmeraldeño una clasificación más certera, para lo cual se deberá explorar su relación de contacto con otras lenguas que bien podrían haber contribuido a su acervo léxico-gramatical sin estar emparentadas, como el cha'palaa o el tsa'fiki, pero también lenguas de origen africano (Adelaar, 2005: 243). Recordemos que según los informes de Stevenson, el esmeraldeño era hablado por zambos (cf. supra), seguramente herederos de los negros de Illescas. Al respecto no podemos dejar de mencionar cierta contradicción a la hora de identificar a los hablantes originarios del esmeraldeño. Jijón los considera iguales a los Caráquez, que habitaban la bahía del mismo nombre. Sin embargo, si los negros de Illescas se mezclaron con los campaces y adoptaron su lengua, y los campaces son en realidad los colorados o tsáchilas como asegura el mismo Jijón (1941: II-103), entonces no es posible que fueran éstos los que dieron su lengua a los zambos que resultaron de la mezcla, porque entonces habría sido relativamente fácil clasificar al esmeraldeño como una lengua barbacoa, cosa que sin duda no lo es, pese a ciertas palabras encontradas, debidas más al contacto que a una afinidad estructural (Adelaar, 2004: 160). Por lo tanto, lo más factible es que los campaces con quienes se mezclaron los negros de Illescas no hayan sido ni los chachis ni los tsáchilas, sino los mismos caraques o una parcialidad septentrional de ellos. Por su carácter incorporante, el esmeraldeño difiere de las lenguas barbacoas, aunque comparte con ellas algunos rasgos como el uso prolífico de clasificadores. Aun así, nada tiene de aventurado explorar otra alternativa: que el esmeraldeño, o mejor dicho, que la lengua que recogió Pallares en 1877, sea más bien un pidgin resultante de la mezcla del esmeraldeño originario y alguna lengua africana, salpicado con contribuciones léxicas y posiblemente gramaticales de las lenguas barbacoas circundantes. Ésta es una opción del todo viable en situaciones de contacto como la surgida a raíz de la llegada de esclavos africanos a las costas esmeraldeñas, pero requiere de una investigación más profunda de los datos lingüísticos e históricos disponibles.

22 Según este autor, Bahía de Caráquez habría estado habitada más bien por hablantes de la lengua cara, que posteriormente se difundió al norte del callejón interandino (Paz y Miño 1961: 13). 


\section{Criterios metodológicos para la investigación toponímica y antroponímica}

Realizar deslindes lingüísticos en un área tan amplia como la costa centro-sur del Ecuador a partir de datos exclusivamente toponímicos y antroponímicos, que son los únicos disponibles, es, por decir lo menos, una empresa arriesgada. Por ello, se hace necesario andar con pies de plomo y tener presente varios criterios de carácter metodológico así como algunas reglas prácticas que permitan un mejor y más correcto manejo de los datos. A continuación esbozamos algunos de estos criterios, capitalizando sobre varios trabajos anteriores de toponimia y antroponimia que nos han enseñado las buenas y las malas prácticas en este campo.

El trabajo de campo y la investigación de archivo en el estudio toponímico-antroponímico

Como hemos podido verificar a partir de nuestro estudio de las fuentes publicadas, las cartas disponibles para la región litoral y el índice de nombres toponímicos, existen al menos tres tipos de problemas que deben ser tomados en cuenta: el primero es que las fuentes publicadas son relativamente recientes y, por lo tanto, no contienen toponimia originaria, sobre todo para aquellas zonas que sufrieron un proceso temprano de castellanización, entre ellas la costa centro-sur ${ }^{23}$; el segundo tiene que ver con lo incompleto de los datos, con lo cual a menudo se consignan sólo topónimos conocidos a nivel nacional, regional o zonal, dejando de lado muchos de tipo local que tienen significado socio-histórico sólo para una pequeña población; el tercero es el problema de la escritura y la representación de sonidos no castellanos, según la cual se imita a menudo el patrón silábico del castellano y las reglas ortográficas de esta lengua, con la consiguiente deformación de los nombres geográficos originarios ${ }^{24}$.

Las anteriores son razones más que suficientes no sólo para ser cautelosos en el tratamiento de los topónimos, sino para verificarlos de dos maneras: la primera, in situ, a través del uso en el habla de la gente local; la segunda, en archivos, es decir, a través del registro de sus antiguas formas escritas, como aparecen, por ejemplo, en expedientes sobre litigios de tierras, para el caso de los topónimos, o en actas bautismales, para el caso de los antropónimos. Lo anterior significa que el estudio de las listas de topónimos y antropónimos debe ir siempre acompañado de un cotejo sincrónico a través de la investigación de campo ${ }^{25}$ y un cotejo diacrónico a través de la investigación de fuentes de archivo.

\section{Utilización crítica de las fuentes desde una perspectiva interdisciplinaria}

El lingüista, como el arqueólogo, hace hablar a los datos poniéndolos en relación unos con otros y analizándolos dentro de un marco que permite su adecuada comprensión. Este hacer que los datos hablen no se logra en el estudio toponímico o antroponímico con datos puramente lingüísticos, más aún si éstos pertenecen a lenguas extintas de las cuales son el único rastro. Tomemos un ejemplo. La final -pi, que a menudo se asocia con el significado de 'agua' o 'río' en lenguas barbacoas, aparece vinculada no sólo con fuentes o corrientes de agua sino también con

23 Por ejemplo, en la carta de la zona de Chanduy producida por el IGM aparece el topónimo San Rafael, de obvio origen hispánico. Sin embargo, el nombre original del pueblo al que se refiere el topónimo es Guaguelsán, relacionado con otro de la misma zona, Sumulsán, ambos de origen prehispánico.

24 Los mejores ejemplos para la Costa son dos. El topónimo 'Pasao', que aparece en las primeras crónicas y relaciones geográficas, se vierte en los diccionarios e índices toponímicos como 'Pasado', por semejanza con el vocablo castellano. Asimismo, 'Engabao', que en algunas listas aparece incluso como 'Engabado', aparece en documentos coloniales tempranos solamente como 'Gabao', es decir, con la misma final -ao que el anterior pero con la añadidura de un prefijo castellano.

25 La verificación in situ permite además registrar además la función del elemento geográfico al que se refiere un topónimo y obtener así información para interpretar su significado. 
lugares de otro tipo. Así, Chigüilpe (< Chigüilpi) es el nombre de una comuna tsáchila, pero su significado sólo puede interpretarse acertadamente si conocemos la geografía local. En efecto, el nombre de la comunidad proviene del río que la atraviesa, el Chigüilpe, cuya etimología a su vez puede variar desde la perspectiva que se mire. Para sus pobladores Chigüilpe proviene de chigüi, especie de caracol pequeño que prolifera en las márgenes del río. Para otros el nombre se origina más bien en chigüila 'piña'. Para discernir correctamente entre ambas interpretaciones hay que tomar en cuenta que chigüi es una palabra propia del tsa'fiki mientras que chigüila es un préstamo kichwa relativamente tardío. Desde este punto de vista, la primera de las etimologías es mucho más probable que la segunda, sin excluir con ello la posibilidad de un topónimo híbrido. Sin embargo, aceptar un topónimo híbrido sin el debido análisis puede llevarnos a relaciones filogenéticas desatinadas. De hecho, fueron etimologías híbridas las que llevaron a un conocido estudioso de las lenguas precolombinas del Ecuador a proponer a principios del siglo pasado que el tsa'fiki y el kichwa pertenecían a una misma familia (Buchwald, 1909, 1918). Hoy en día sabemos que el tsa'fiki junto con el cha'palaa y el awapit pertenecen a una familia de lenguas (barbacoas) que nada tienen que ver con el kichwa, pese a lo cual sabemos también que entre los hablantes de ambas lenguas existió un estrecho contacto de varios siglos que produjo préstamos léxicos de lado y lado (Gómez Rendón, en preparación). Todo esto sirve para señalar el cuidado que nos debe asistir en el manejo de las fuentes y la cautela en las conclusiones. A propósito de un uso interdisciplinario de las fuentes para la correcta interpretación toponímica, referimos al lector al estudio Toponimia histórica, arqueología y formas prehispánicas de agricultura en la Región de Otavalo (Caillavet, 1983), donde su autora conjuga de manera acertada, en nuestra opinión, fuentes históricas, arqueológicas y socioeconómicas a fin de interpretar las terminaciones más comunes de los topónimos encontrados en la zona de Otavalo.

En este punto es preciso un comentario sobre lo que hoy se conoce como etimologías populares y falsas etimologías. Se entiende las primeras como aquellas que provienen de una interpretación del dato toponímico a partir de circunstancias presentes o, por lo menos, relativamente recientes, es decir, a partir de información que se encuentra dentro de la memoria individual y/o colectiva de los hablantes. Claro ejemplo de ello es la interpretación que el autor recogió del topónimo sinchal - comuna del valle de Valdivia - por parte de algunos de sus habitantes. Según dicha interpretación, que estaba incluso consignada en una monografía preparada por un maestro de la comuna hace algunos años, el topónimo se había originado en el hecho singular de que durante una reunión de miembros de las distintas comunas del valle, los habitantes de la comuna en cuestión habrían asistido "sin chal", es decir, sin cubrirse con esta prenda de vestir, a diferencia del resto de personas. Luego de indagar con varios de los más ancianos de la comuna, supimos que una prenda semejante nunca había sido utilizada en el pasado. Al proseguir la investigación, tuvimos ocasión de encontrar el expediente que recoge el litigio que siguen los indios de Colonche contra los de la Punta por haberse apoderado éstos de un sitio ancestral suyo (ca. 1798). En dicho expediente identificamos, entre otros, el topónimo 'Sinchal' en referencia al sitio donde actualmente se encuentra la comunidad que lleva este nombre. Como es obvio, la hipótesis más plausible es que el origen del topónimo no sea hispánico sino prehispánico, quizá el mismo de topónimos como Chinchinal, Sanguangal, o Nanegal, y muchos otros encontrados en la zona de influencia de las lenguas barbacoas. Aunque la interpretación dada por los habitantes puede resultar errónea desde una perspectiva diacrónica, no deja de resultar interesante desde un punto de vista sincrónico, desde el cual refleja - o puede reflejar - criterios de identidad o auto-identificación que sirven a sus hablantes para marcar diferencias con otros grupos vecinos, con los cuales pueden estar en competencia por el acceso a los recursos, por ejemplo. En esta medida, la interpretación popular del topónimo no sólo es legítima sino que puede resultar esclarecedora.

Otro es el caso de las falsas etimologías, que se distinguen de las anteriores en la medida que la información sincrónica en que se apoyan no nace de la experiencia de los sujetos que utilizan el topónimo, sino de las impresiones, prejuicios, ideas o divagaciones del investigador. En este caso la interpretación es ilegítima porque parte de supuestos ajenos a la experiencia histórica, social, 
económica y cultural de los usuarios del topónimo. Es de lamentar que un número importante de estudios toponímicos hagan uso y abuso de falsas etimologías para explicar el supuesto significado de voces prehispánicas (Salazar, 1991: 93). Esta práctica ha sido frecuente y debe ser desterrada de una vez por todas de los círculos académicos y de investigación, pues crea más confusiones de las que pretende resolver. Los puntos de partida de las falsas etimologías son dos. Uno es la segmentación incorrecta de los elementos morfológicos de una palabra, provocada a su vez por una incomprensión de las leyes del cambio fonético, de la cual ni siquiera investigadores meticulosos han podido salvarse, como señalamos arriba a propósito de las críticas hechas al trabajo de Jijón y Caamaño. Otro punto de partida de las falsas etimologías consiste en una petición de principio, es decir, en dar por supuesto aquello que precisamente se quiere comprobar. Así, por ejemplo, no podemos segmentar una palabra en raíces y terminaciones del tsa'fiki o del cha'palaa cuando de lo que se trata es precisamente de saber si tal palabra proviene o no de dicha lengua, para lo cual no se puede partir de un análisis de sus componentes sino más bien de un estudio de su distribución areal y de las culturas asociadas con sus posibles hablantes. Sólo cuando se ha establecido como efectiva la posibilidad de un parentesco, se pueden ensayar glosas de un topónimo a partir de lo que se conoce de otras lenguas. Este proceso es más necesario todavía para el caso que nos ocupa, donde desconocemos el perfil lingüístico de las lenguas que queremos analizar, los significados de sus raíces o incluso los procesos de formación de palabras. Con estos antecedentes comprenderá el lector que en este estudio no intentemos ofrecer una interpretación de las voces prehispánicas y que empecemos más bien por identificar segmentos válidos y determinar su distribución areal para asociarlos luego con determinado grupo social o sub-área cultural.

El análisis lingüístico de los datos: desarrollos teóricos y bases de datos digitales

Cuando se realizó el principal estudio toponímico-antroponímico de las lenguas prehispánicas del Ecuador en la primera mitad del siglo pasado, el método comparativo se había consolidado en la lingüística como una de las principales herramientas para explorar las relaciones genéticas entre las lenguas. Para entonces estaba en su apogeo la lingüística estructural y su método de estudiar las relaciones entre los elementos que forman parte del sistema de la lengua en sus distintos niveles, a partir de los ejes sincrónico y diacrónico. A pesar de los importantes avances en la teoría lingüística desde entonces, el análisis estructural de la lengua persiste de una u otra forma en la lingüística actual. Sin embargo, el conocimiento más profundo obtenido recientemente del funcionamiento de los niveles lingüísticos y su interrelación, así como los avances en la descripción de las diferentes lenguas del mundo, han potenciado el análisis con el uso de técnicas refinadas. Hoy en día es importante conocer y aplicar estas técnicas al estudio de la toponimia si queremos obtener resultados fidedignos. Como vimos en secciones anteriores, las fallas en la identificación del origen de topónimos y antropónimos se basan en la segmentación incorrecta de las series, con el resultado de raíces y finales que no coinciden en todos los casos pero cuya relación se fuerza para hacerla comprensible a la interpretación general. Al respecto, conviene señalar que no existe una equivalencia sistemática entre sonidos relacionados y no relacionados, y que dicha equivalencia se puede establecer sólo a posteriori, es decir, luego de analizado todo el sistema fonológico de una lengua. Por ejemplo, los segmentos fónicos /i/ y /e/ pueden ser similares en cuanto al rasgo de anterioridad, pero ello no significa necesariamente que sean equivalentes y por lo tanto alófonos de un mismo fonema. El ejemplo más a la mano viene del kichwa. En esta lengua los segmentos /i/ y /e/ no son fonemas distintos sino variantes alofónicas, cosa que no ocurre, por ejemplo, en castellano, donde el sistema los trata como sonidos significativamente distintos. Igual cosa se puede decir de la nasalidad, que en lenguas barbacoas como el awapit y el tsa'fiki es un rasgo distintivo de las vocales, lo que significa que su presencia provoca diferencias de significado, lo que no ocurre en castellano, donde la nasalidad 
es un simple matiz vocálico que no altera la semántica. Es necesario que estemos al tanto de estas diferencias estructurales, sobre todo si analizamos material de lenguas cuyo sistema fonológico nos es desconocido; de lo contrario corremos el riesgo de utilizar criterios fonológicos de nuestra propia lengua en el análisis de segmentos fónicos de otra, cuya estructura es completamente diferente. Asimismo, debemos tener en cuenta los criterios básicos de descripción fonética, por cuanto permiten describir mejor los procesos de cambio de sonidos y establecer la relación entre segmentos disímiles a primera vista.

Otro punto tiene que ver con la manera de analizar la información. El copioso acervo de datos toponímicos y antroponímicos que presentan estudios dedicados al tema, sobre todo los ya mencionados de Jijón (1940-45) y Paz y Miño (1961-4), fue preparado en una época en que no existían herramientas informáticas digitales, por lo que su análisis fue exclusivamente manual. En principio no hay ningún problema con un análisis manual, pero la posibilidad de error aumenta proporcionalmente a la cantidad de datos que se analizan. En la actualidad existen poderosas herramientas que pueden facilitarnos el trabajo y que no debemos dudar en utilizar para obtener mejores y más eficaces resultados. En este sentido se hace imprescindible construir bases digitales de los datos toponímicos para facilitar su análisis. Una herramienta poderosa son los programas para la confección de diccionarios digitales, los cuales permiten no sólo un acceso instantáneo a los datos en tiempo real sino que ofrecen herramientas de búsqueda, ordenamiento desde inicio o final de palabra, etiquetado y glosas. Otra herramienta de gran utilidad para el análisis toponímico son los segmentadores semiautomáticos, programas que permiten construir léxicos de morfemas ligados o libres, a partir de los cuales se analizan los datos ingresados, permitiendo además la edición permanente de dichos léxicos conforme avanza el análisis. Para los fines del presente estudio hemos creado tres bases de datos digitales en un segmentador semiautomático (Toolbox), las mismas que una vez analizadas se han transferido automáticamente a otro programa (Lexique Pro) que las ordena por orden alfabético normal e inverso, permitiendo su visualización inmediata y comprensiva. Estamos seguros de que el uso de estas herramientas optimizará el análisis de los datos toponímicos y antroponímicos y, utilizadas con criterios técnicos de descripción lingüística, permitirán obtener resultados más sistemáticos y veraces en el menor tiempo posible.

\section{Bibliografìa}

Acosta-Solís, Misael. 1948, “Tagua or vegetable ivory - a forest product of Ecuador”. Economic Botany 2, pp. 46-57.

Adelaar, Willem. 2005, "El esmeraldeño - un idioma de la costa del Ecuador". En S. Dedenbach-Salazar Sáenz (ed.), Contribuciones a las lenguas y culturas de los Andes. Homenaje a Alfredo Torero, Aachen: Shaker Verlag, pp. 45-233.

Adelaar, Willem y Peter Muysken. 2007, The Languages of the Andes. Cambridge Language Surveys. Cambridge: Cambridge University Press.

Aikhenvald, Alexandra. 2010, Language contact in Amazonia. Oxford: Oxford University Press.

Álvarez, Silvia. 2001, De huancavilcas a comuneros. Relaciones interétnicas en la Península de Santa Elena, Ecuador. $2^{\mathrm{a}}$ edición. Quito: Abya Yala - CODENPE.

2002, Etnicidades en la Costa Ecuatoriana. Quito: Abya Yala, 2002, 305 págs.

Anónimo. 1994a, "Razón de los indios tributarios que hay en la provincia de la ciudad de Santiago de Guayaquil y del tributo que pagan a los encomenderos en cada un año y de lo que pagan a juez protector y doctrinero (1577)" [19]. En Ponce Pilar comp. Relaciones Histórico Geográficas de la Audiencia de Quito (siglo XVIXIX), Tomo I, Quito: Marka, Abya- Yala.

1994b, "Descripción de la gobernación de Guayaquil, (1604/5)" [52]. En P. Ponce comp. Relaciones Histórico Geográficas de la Audiencia de Quito (siglo XVI-XIX), Tomo II, Quito: Marka, Abya- Yala.

1994c, "Relación de Guayaquil (h. 1772)" [72]. En P. Ponce comp. Relaciones Histórico Geográficas de la Audiencia de Quito (siglo XVI-XIX), Tomo II, Quito: Marka, Abya- Yala. 
Arrizabalaga, Carlos. 2008, “¿Un catecismo tallán? Evangelización en lenguas indígenas en Piura a finales del siglo XVI", s/e.

Bouchard, Jean-François, Franklin Fuentes y Telmo López. 2006, “Aldeas y pueblos prehispánicos en la costa de Manabí: Chirije y Jarapotó”. Bulletin de l'Institut Français d'Études Andines, 35 (3): pp. 243-256.

Buchwald, Otto von. 1909, "Ecuatorianische Grabhügel”. Globus, vol. XCVI, Braunschwieg.

1926, "La zona del Guayas", Boletín de la Biblioteca Nacional de Quito, No. 4.

1918a, "Migraciones sudamericanas". Boletín de la Sociedad Ecuatoriana de Estudios Históricos Americanos, vol. 1 Quito, pp. 225-236.

1919b, "Notas acerca de la arqueología del Guayas", Boletín de la Sociedad Ecuatoriana de Estudios Históricos, Año 1, No. 3, pp. 237-252.

Caillavet, Chantal. 1983, "Toponimia histórica, arqueología y formas prehispánicas de agricultura en la Región de Otavalo - Ecuador'. Bulletin de l'Institut Français d'Études Andines, (3-4): pp. 1-21.

Campbell, Lyle. 1997, American Indian Languages. The Historical Linguistics of Native America. Oxford Studies in Anthropological Linguistics. Oxford: Oxford University Press.

Carmona Moreno, Félix. 1980, Acción pastoral de Luis López de Solís, IV Obispo de Quito, San Lorenzo del Escorial.

Carvajal, Fray Gaspar de. 1894, Descubrimiento del río de las Amazonas según la relación hasta ahora inédita de Fr. Gaspar de Carvajal. Sevilla: Imprenta E. Rasco..

Cieza de León, Pedro. 1922 [1553], La Crónica del Perú. Madrid: Calpe.

Costales, Alfredo y Piedad Peñaherrera. 1961, Llacta Runa. Quito.

Crystal, David. 2006, A Dictionary of Linguistics and Phonetics. 5th Edition. Oxford: Blackwell Publishing.

Damp. Jonathan E. 1984, "Architecture of the Early Valdivia Village". American Antiquity, Vol. 49, No. 3, pp. 573-585.

Dorsey, George. 1901, Archeological investigations of the Island La Plata, Ecuador. Field Museum Natural History, Publication No. 56.

Echeverría Almeida, José. 1996, "Los primeros poblados". En Enrique Ayala Mora (editor). Nueva Historia del Ecuador. Quito: Corporación Editora Nacional, vol. I. pp. 181-222.

Espinoza Soriano, Waldemar. 1988. "El reino de los Chono, al este de Guayaquil, siglos XV y XVI: el testimonio de la arqueología y la etnohistoria". En Historia Ecuatoriana: Estudios y Documentos. Quito: Abya Yala, pp. 125-191.

Estete, Miguel de. 1919. Descubrimiento y conquista del Perú. Boletín de la Sociedad Ecuatoriana de Estudios Históricos Americanos, vol. 1, Quito.

Estrada, Emilio. 1957a, Prehistoria de Manabí. Guayaquil: Museo Víctor Emilio Estrada.

1957b, Últimas civilizaciones prehistóricas de la Cuenca del Río Guayas. Guayaquil: Museo Víctor Emilio Estrada.

1962, Arqueología de Manabí central. Guayaquil: Museo Víctor Emilio Estrada.

Estrada, Emilio y Clifford Evans. 1963, “Cultural development in Ecuador”, Aboriginal Cultural Development in Latin America: an Interpretative Review. Washington D.C.: Smithsonian Institution, pp. 77-88.

Fabre, Alain. 2005, Diccionario etnolingüístico y guía bibliográfica de los pueblos indígenas súdame- ricanos. Edición digital. http://butler.cc.tut.fi/ fabre/BookInternetVersio/Alkusivu.html.

Fauria, Carmen. 1995, "Particularidades de las encomiendas en la costa central andina. En Álvarez, Aureli, et al (eds.) Investigaciones sobre la Costa del Ecuador en Europa, Arqueología, Etnohistoria, Antropología Sociocultural. Quito: Abya Yala.

Fernández de Oviedo y Valdez, Gonzalo. 1855, Historia General y Natural de las Indias, Vol. IV, Madrid.

Gómez Rendón, Jorge. "Quechua lexical and gramatical borrowing in Tsa'fiki”, en preparación.

2008, "Patrimonio lingüístico, lenguas amenazadas y documentación". Revista Nacional de Cultura. No. 13, septiembre.

2010, "Vitalidad de la lengua Tsa'fiki en las siete comunidades Tsa'chilas de la Provincia de Santo Domingo". Informe Final del proyecto de Diagnóstico Sociolingüística de la Lengua Tsa'fiki, Instituto Nacional de Patrimonio Cultural-Quito.

González Suárez, Federico. 1967, Notas arqueológicas y Prehistoria ecuatoriana. Puebla: Editorial J.M. Cajica, Jr.

Greenberg, Joseph. 1956, "The general classification of Central and South American Languages. En Anthony Wallace (ed.) Men and Cultures. Selected papers of the 5th International Congress of Anthropological and Ethnological Sciences. Philadelphia: University of Pennsylvania Press, pp. 4 - 791. 
1987, Language in the Americas. Stanford: Stanford University Press.

Greenberg Joseph and Merritt Ruhlen. 2007, An Amerind Etymological Dictionary. Department of Anthropological Sciences. Stanford: Stanford University.

Hamerly, Michael. 1987, Historia Social y económico de la Antigua provincia de Guayaquil, 1763- 1842. Banco Central del Ecuador. Guayaquil: Archivo Histórico del Guayas.

Hocquenghem, Anne-Maríe. 2010, "El spondylus princeps y la edad de bronce en los andes centrales: Las rutas de intercambios". En Emiliano Melgar Tísoc, Reyna Solís Ciriaco, Ernesto González Licón (eds.) Producción de Bienes de Prestigio, Ornamentales y votivos de la América Antigua. Serie Arqueológica Mesoamericana. México: Syllaba Press, pp. 34-49.

Hocquenghem, Anne-Maríe, Jaime Idrovo, Peter Kaulicke, y Dominique Gomis. 1993, "Bases del intercambio entre las sociedades norperuanas y surecuatorianas: una zona de transición entre 1.500 A.C. Y 600 D.C", Bulletin de l'Institut Français d'Études Andines, 22 (2): 243-256.

Instituto Geográfico Militar. 2009, "Propuestas para la creación de la Junta Nacional de Topónimos”. Documento de Trabajo. Quito.

Jijón y Caamaño, Jacinto. 1919, "Contribución al conocimiento de las lenguas indígenas que se hablaron en el Ecuador Interandino y Occidental, con anterioridad a la Conquista Española. Ensayo Provisional”. Boletín de la Sociedad Ecuatoriana de Estudios Históricos Americanos, No. 6, edición especial, Quito.

1988, El ecuador interandino y occidental antes de la conquista castellana. Quito: Editorial Ecuatoriana, vol. 1 (1940), vol. 2 (1941), vol. 3 (1943), vol. 4 (1945). Quito: Abya Yala, edición facsimilar.

Lathrap, Donald, Jorge G. Marcos y James A. Zeidler. 1977, "Real Alto: an Ancient Ceremonial Center", Archaeology, 30:1, pp. 2-13.

León Borja de Szászdi, Dora. "Prehistoria de la costa ecuatoriana", Anuario de Estudios Americanos, vol. 21, pp. 381-436.

López de Gómara, Luis. 1858, "La entrada que Gonzalo Pizarro hizo á la tierra de la Canela". En Historiadores Primitivos de Indias. Tomo Primero. Biblioteca de Autores Españoles desde la formación del lenguaje hasta nuestros días. Madrid: M. Rivadeneira.

Marcos, Jorge. 1985, "Los Campos elevados de la Cuenca del Guayas, Ecuador: El Proyecto Peñón del Río. PreHispanic Agricultural Fields in the Andean Region, Parte II, W. Denevan, K. Mathewson y G. Knapp. Actas del 45o Congreso Internacional de Americanistas, Bogotá, Colombia, 359 (II): pp. 217-224).

1995, "El mullu y el pututo: la articulación de la ideología y el tráfico a larga distancia en la formación del estado Huancavilca”. En Primer encuentro de investigadores de la costa ecuatoriana en Europa: arqueología etnohistoria, antropología sociocultural, Quito: Abya Yala, pp. 97-142.

McEwan, Collin. 2003, And the sun sits in his seat: creating social order in Andean culture. Ph.D. Dissertation, University of Illinois, Urbana-Champaign.

Meggers, Betty J. 1966, Ecuador. Londres: Thames and Hudson.

Montufar y Fraso, Juan Pío. 1994, "Razón sobre el estado y gobernación política y militar de las provincias, ciudades, villas y lugares que contiene la jurisdicción de la Real Audiencia de Quito (1754)" [63]. En Relaciones Histórico Geográficas de la Audiencia de Quito (siglo XVI-XIX), P. Ponce comp. Tomo II, Quito: Marka, Abya- Yala.

Newson, Linda A. 1995, Life and Death in Early Colonial Ecuador. The civilization of the American Indian Series, No. 214. Oklahoma: University of Oklahoma Press.

Palop Martínez, Josefina. "Mapa étnico del sur de Colombia y norte del Ecuador durante los siglos XVI-XVII". Revista Española de Antropología Americana 24, 139-153.

Paz y Miño, Luis Telmo. 1961, "Las agrupaciones y lenguas indígenas del Ecuador en 1500 y 1959”. Boletín de la Academia Nacional de Historia, Vol. 43, No. 97.

1961 - 1964 "Las lenguas indígenas del Ecuador. Diccionario Toponímico". Boletín de la Academia Nacional de Historia, Vol. XLIII-LVIX, Nos. 98-.

Pérez Pimentel, Rodolfo. 2003, El Ecuador Profundo. Guayaquil, 4, vols. Edición Digital. URL: http://www. ecuadorprofundo.com.

Quilter, Jeffrey, Marc Zender, Karen Spalding, Régulo Franco Jordán, César Gálvez Mora y Juan Castañeda Murga. "Traces of a Lost Language and Number System Discovered on the North Coast of Peru", American Anthropologist, Vol. 112, Issue 3, pp. 357-369.

Ramírez Ángel. 2010, “Estudio Histórico del Devenir de las Comunas del Valle de Valdivia”. Informe del Proyecto Valdivia, Instituto Nacional de Patrimonio Cultural-Guayas, Quito.

Ramos Cabredo, Josefina. 1950, "Ensayo de un vocabulario de la lengua Tallán o Tallanca", Cuadernos de 
Estudio, Instituto de Investigaciones Históricas de la Pontificia Universidad Católica del Perú, tomo IV, No. 3, anexo C, pp. 11-55, Lima.

Requena y Herrera, Francisco. 1994, "Descripción histórica y geográfica de la provincia de Guayaquil, (1774)"

[73]. En Relaciones Histórico Geográficas de la Audiencia de Quito (siglo XVI-XIX), P. Ponce comp. Tomo II, Quito, Marka, Abya- Yala, 1994.

Rivet, Paul. 1942, “Un dialect hoka colombien: le yurimangi”. Journal de la Société des Américanistes, 34: pp. 1-59, París.

Rivet, Paul y Henri Beuchat. 1907, "Contribution à l'étude des langues Colorado et Cayapa". Journal de la Société de Américanistes Paris 4/1: 31-70.

Rostworowski, María. 1975, "Pescadores, artesanos y mercaderes costeños del Perú prehispánico", Revista del Museo Nacional 41, pp. 309-349.

Salazar, Ernesto. 1991, "Vida y Pasión de los Topónimos". Revista Ecuatoriana de Historia, No. 1. Quito: Corporación Editora Nacional.

Sámanos, Juan de. 1884 [1526], "Relación de los primeros descubrimientos de Francisco Pizarro y Diego de Almagro. Colección de Documentos Inéditos para la Historia de España. Vol. V, Madrid.

Sapir, Edward. 1921, Language. An Introduction to the Study of Speech. New York: Harcourt Brace.

Saville, Marshall H. 1907, The Antiquities of Manabi, Ecuador. A Preliminary Report. Contributions to South American Archeology, Vol. 1. New York: Irving Press.

Schwarz, Frederick A. y J. Scott Raymond. 1996, "Formative Settlement Patterns in the Valdivia Valley, SW Coastal Ecuador". Journal of Field Archeology. Vol. 23, No. 2, pp. 205-224.

Seler, Eduard. "Die sprache der Indianer von Esmeraldas". En Eduard Seler. Gesammelte Abhandlungen zur altamerikanishen Sprach- und Alterthumskunde, Vol. 1, pp. 49-64, Berlín: A. Asher \& Co.

Stark, Louisa. 1968, Mayan Affinities with Yunga of Peru. PhD Dissertation. New York University.

1972, "Maya-Yunga-Chipaya. A new linguistic alignment". International Journal of American Linguistics, 38, 2 , pp. 119-135.

Stothert, Karen E. "Review of the Early Preceramic Complexes on the Santa Elena Peninsula, Ecuador", American Antiquity, vol. 48, No. 1.

1988, La prehistoria temprana de la Península de Santa Elena: Cultura Las Vegas. Guayaquil: Museos del Banco Central del Ecuador.

1985, “The Preceramic Las Vegas Culture of Coastal Ecuador”, American Antiquity, 50:3, pp. 613-637.

Torero, Alfredo. 1986, "Deslindes lingüísticos en la costa norte peruana". Revista Andina, Año 4, No. 2, dic. pp. 523-548.

1988, "Áreas toponímicas e idiomas en la sierra norte peruana. Un trabajo de recuperación lingüística". Revista Andina, No. 13, pp. 217-257.

2002, Idiomas de los Andes. Lingüística e Historia. Instituto Francés de Estudios Andinos. Lima: IFEA - Editorial Horizonte.

Torres Fernández de Córdova, Glauco. 2002, Lexicón Etnolectológico del Quichua Andino. Cuenca: Tumipanpa, 3 vols.

Vacas, Sebastián. 2010, "Estudio Antropológico de las Comunas del Valle de Valdivia". Informe del Proyecto Valdivia, Instituto Nacional de Patrimonio Cultural-Guayas, Quito.

Wolf. Teodoro. 1892, Geografía y geología del Ecuador. Leipzig: Tipografía de F. A. Brockhaus.

Zeidler, James Anthony. "Maritime Exchange in the Early Formative Period of Coastal Ecuador: Geopolitical Origins of Uneven Development", Research in Economic Anthropology, Vol. 13: pp. 247-268.

Zevallos Menéndez, Carlos. 1992, Nuestras Raíces Huancavilcas.

Fuentes primarias:

"Indios de Chanduy y Colonche para que se les exima del servicio de vigías" (AHG EP/J 2459 [1803]).

"Pedro Chaparro y Manuela Tomalá, caciques principales del pueblo de Baba, contra Marcos Avellán sobre la nulidad de una compra hecha a Manuela Tomalá de una parte del sitio de Carrizal" (AHG, EP/J 6032 [1806]).

"Litigio por el pueblo de Colonche en el partido de Santa Elena sobre el despojo que le infieren los naturales vecinos del pueblo de la Punta en sus sitios de la Cueva y Carrizal" (AHG, EP/1153 [1810-13]). 


\section{ANEXOS}

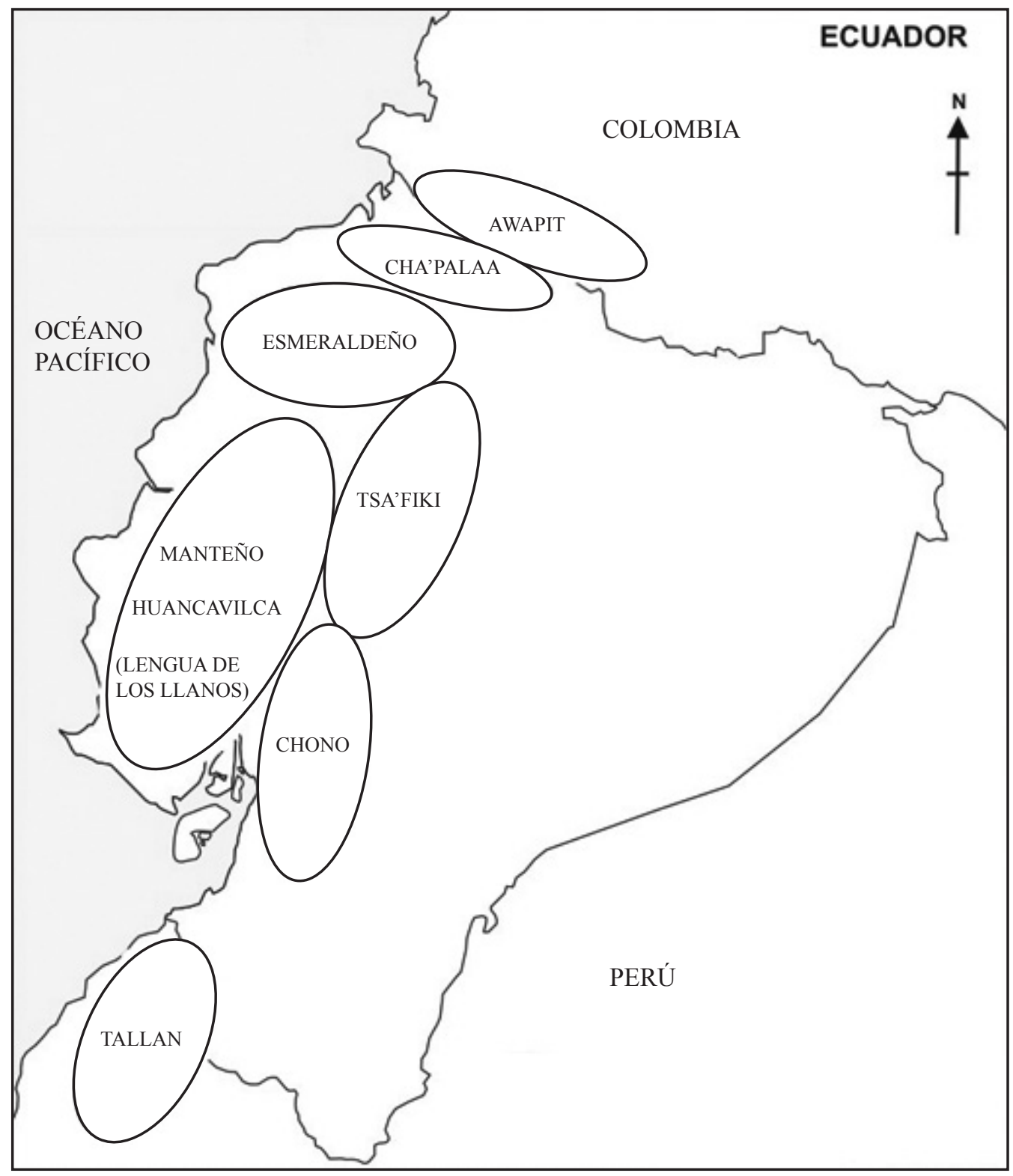

Mapa 1. Lenguas indígenas de la Costa (s. XV-XVI) 


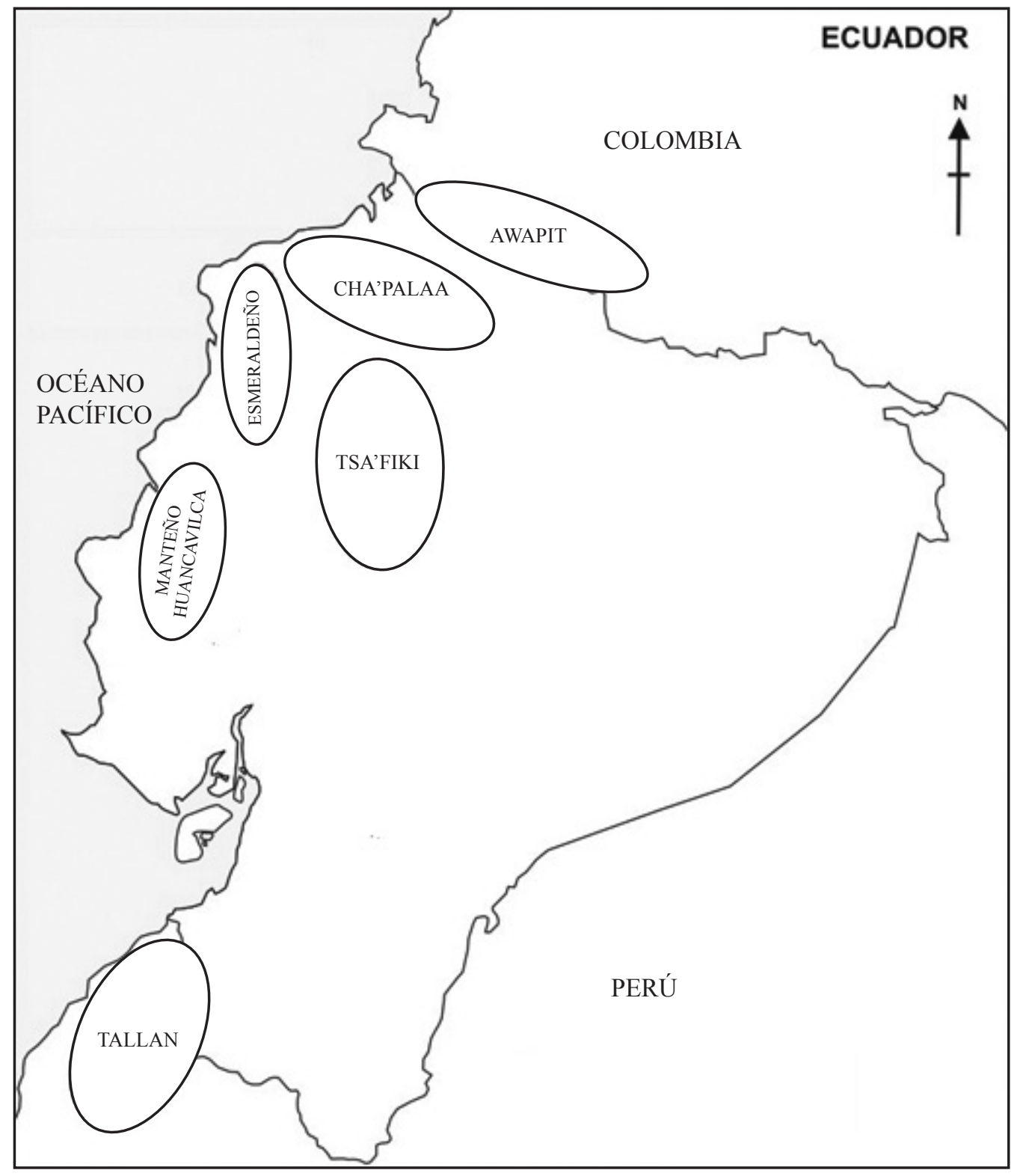

Mapa 2. Lenguas indígenas de la Costa (s. XVI-XIX) 
DESLINDES LINGÜÍSTICOS EN LAS TIERRAS BAJAS DEL PACÍFICO ECUATORIANO

| 107

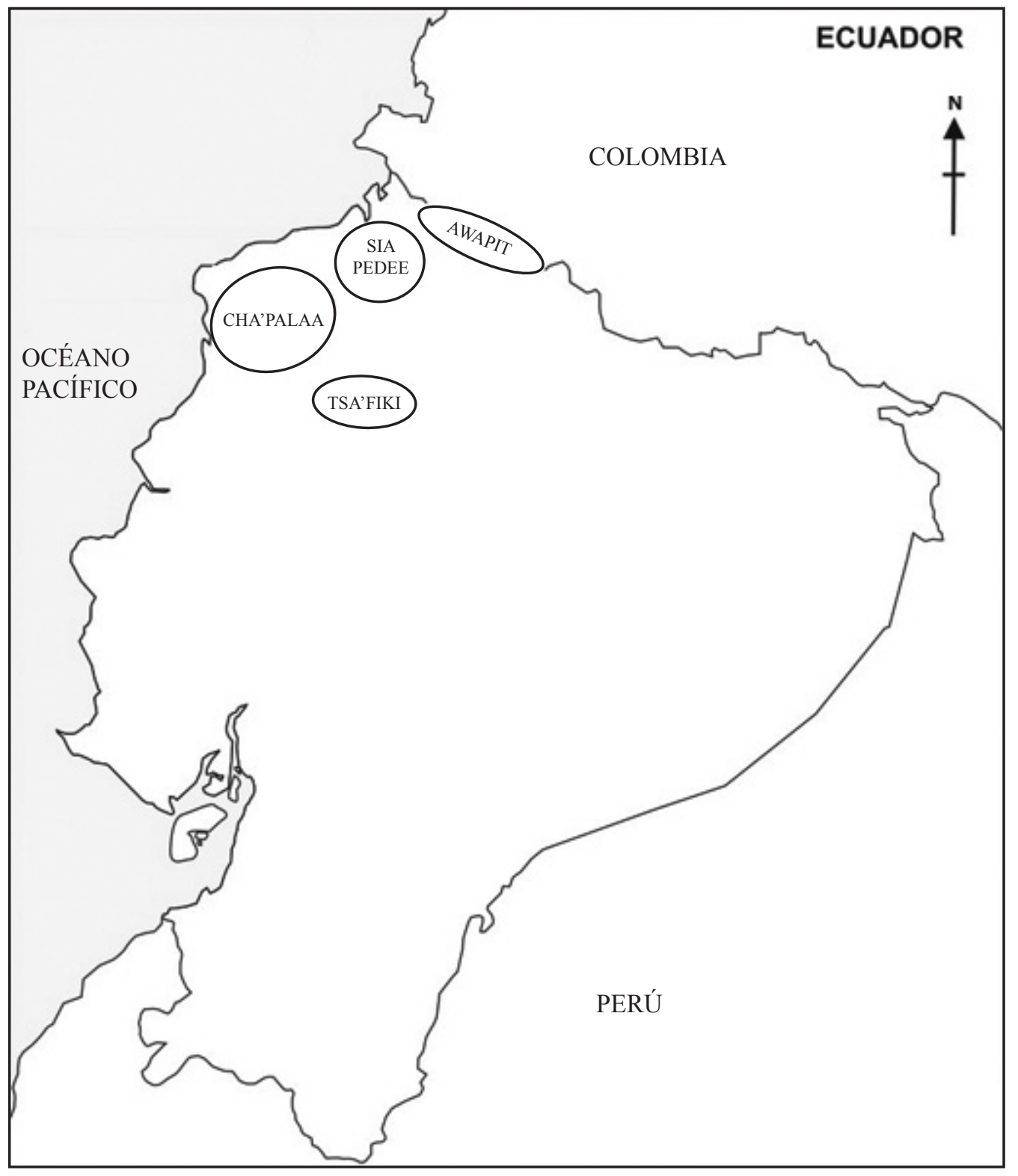

Mapa 3. Lenguas indígenas de la Costa (s. XX-XXI) 